\title{
Altered updating of bodily and spatial representations following tool-use in Complex Regional Pain Syndrome
}

Vitters $\emptyset$, Axel D. ${ }^{a, b, c} *$; Buckingham, Gavin ${ }^{c}$; Halicka, Monika ${ }^{a, b}$; Proulx, Michael J., ${ }^{b, d}$; Bultitude, Janet $H^{a, b}$

${ }^{a}$ Centre for Pain Research, University of Bath, Bath, Somerset, United Kingdom

${ }^{b}$ Department of Psychology, University of Bath, Bath, Somerset, United Kingdom

'Department of Sport \& Health Sciences, University of Exeter, Exeter, Devon, United Kingdom

${ }^{d}$ Centre for Real and Virtual Environments Augmentation Labs, Department of Computer Science, University of Bath, Bath, Somerset, United Kingdom

${ }^{*}$ Corresponding author

Email: a.d.vitterso@bath.ac.uk

Phone: +44 1225386226

Address: Department of Psychology, 10 West, University of Bath, Claverton Down, Bath, BA2 7AY, United Kingdom

URL: https://www.bath.ac.uk/research-centres/centre-for-pain-research-cpr/

Number of text pages (including figures \& tables): 52

Number of figures: 6

Number of tables: 2

Conflict of interest:

The authors have no conflicts of interest to report.

Previous presentation of the research:

The results of this study were presented at European Somatosensation \& Body Representation meeting (2019); Scandinavian Association for the Study if Pain's congress (2019); and Federation of the European Societies of Neuropsychology's $7^{\text {th }}$ scientific meeting (2019). 


\section{Abstract}

Distorted representations of the body and peripersonal space are common in Complex Regional Pain Syndrome (CRPS), and might modulate its symptoms (e.g. asymmetric limb temperature). In painfree people, such representations are malleable, and update when we interact with objects in our environment (e.g. during tool-use). Distortions are also common after immobilisation, but quickly normalise once movement is regained. We tested the hypothesis that people with CRPS have problems updating bodily and spatial representations, which contributes to the maintenance of their distorted representations by preventing normalization. We also explored spatially defined modulations of hand temperature asymmetries, and any influence of updating bodily and spatial representations on this effect. Thirty-six people with unilateral CRPS (18 upper limb, 18 lower limb) and 36 pain-free controls completed tool-use tasks considered to alter body and peripersonal space representations (measured using tactile distance judgements and a visuotactile crossmodal congruency task, respectively). We also tested how the arrangement (crossed, uncrossed) of the hands and tools affected hand temperature. In upper limb CRPS the non-affected arm representation updated normally, but the affected arm representation updated in the opposite to normal direction. A similar pattern was seen in lower limbs CRPS, although not significant. Furthermore, people with CRPS showed more pronounced updating of peripersonal space than the controls. We did not observe any modulation of hand temperature asymmetries by the arrangement of hands or tools. Our findings suggest enhanced malleability of bodily and spatial representations in CRPS, potentially implicating central mechanisms in the aetiology of this condition. 


\section{Introduction}

Distorted representations of the body and its surrounding (i.e. peripersonal) space are characteristic of certain neurological conditions, and can be present in chronic pain $[23,68,79]$. For instance, aside from pain, motor deficits, and autonomic symptoms, people with Complex Regional Pain Syndrome (CRPS) typically perceive their affected limb to be larger than its physical size, and can report feelings of missing body parts $[1,51,59,67]$. There is also evidence of attentional biases away from the CRPSaffected side of peripersonal space $[9,21,56,62]$, which are predicted by body representation distortions [9].

Bodily and spatial representations are use-dependent: they update if our ability to use our limbs is restricted temporarily (e.g. by casting [25]) or permanently (e.g. by amputation $[11,38]$ ), or as we interact with objects $[17,36,40,44,46,64]$. One paradigm that demonstrates the malleability of bodily and spatial representations is tool-use. Tool-use causes the multisensory representations of the body and peripersonal space to update $[13,40,44]$, whereby the nervous system changes the way it uses sensory information to enable tools to become functional and sensory extensions of the body [49]. For example, using rake-like tools leads to a perceived lengthening of arm and extends peripersonal space towards the distal end of the tool [12]. Tool-use thus enables research into the malleability of bodily and spatial representations.

Distorted representations of the body and peripersonal space might contribute to CRPS pathology by leading to conflicts between sensory and motor signals theorised to trigger pain and other symptoms [27,45]. Altered body representation and effortful movement ("neglect-like symptoms") are predictive of worse pain outcomes in chronic CRPS six months later [85]. Treatments that target bodily and spatial representation, such as graded motor imagery [50,52,53], and prism adaptation 
$[8,14,74]$ can reduce pain and other CRPS symptoms [6]. Furthermore, hand temperature asymmetries can be reduced by crossing the CRPS-affected hand into the non-affected side of peripersonal space [55].

Altered bodily and spatial representations are common after limb immobilisation $[4,25,35]$, but these effects typically reverse once normal movement is restored [3]. As the distorted representations in CRPS persist, this could be due to problems with updating such representations. Here, we present a study investigating the updating of body and peripersonal space representations following tool-use in people with and without CRPS. We used tactile distance judgements (TDJs) $[4,12,47,48]$ and a crossmodal congruence task (CCT) [42] to examine tool-use-dependent changes in body and peripersonal space representations, respectively. We hypothesised that people with CRPS would be less able to update bodily and spatial representations than pain-free individuals, as indicated by different effects of tool-use on their TDJs and CCT responses.

Furthermore, since CRPS symptoms can be spatially modulated [55], and this effect appears dependent on the represented location in space rather that the limb's physical position [54], we adapted previous protocols $[54,55]$ to explore any modulation of hand temperature asymmetry by the arrangement of embodied tools. We hypothesised that hand temperature asymmetries would be reduced when people with upper limb CRPS rested their hands - or, post tool-use, the tools - in a crossed, compared to uncrossed, arrangement.

\section{Method}

\subsection{Design}


We used a mixed design with one session to measure tool-use-dependent changes in the representations of the body and peripersonal space, and hand temperature asymmetry. We compared these variables between people with upper limb CRPS, lower limb CRPS, and pain-free individuals. In line with recent recommendations for pain research [30], the study protcol and planned analyses were preregistered on the Open Science Framework (https://osf.io/pidw9).

\subsection{Participants}

The inclusion criteria for all participants in the study were that they be aged over 18 , have normal or corrected to normal vision, and have sufficient arm strength to manoeuvre the tools. Exclusion criteria were a history of brain injury or disorder (e.g. stroke, multiple sclerosis, Parkinson's disease), or psychiatric disorders that might be associated with pronounced perceptual changes (e.g.

schizophrenia [80]). We did not exclude participants who reported a history of depression or anxiety. Additional inclusion criteria for people with CRPS were that they met the Budapest research criteria for CRPS type I or II [26] primarily affecting one upper or one lower limb. Additional exclusion criteria for the pain-free controls were that they had chronic pain (defined as having experienced pain most days for 3-months or more). Control participants were matched to an individual with CRPS for age ( \pm 5 years), sex, and self-reported handedness. Participants were reimbursed $£ 10$ per hour for their time, along with travel and accommodation expenses where relevant. The study adhered to the 2013 Declaration of Helsinki, and received ethical approval from the UK Health Research Authority (REC reference 12/SC/0557) and the University of Bath Psychology Department Ethics Committee (16-236).

Our sample size calculations for a 4-way repeated-measures ANOVA suggested that 17 participants would be needed in each group to detect a medium effect size $(f=0.25)$, with an alpha of 0.05 , and $80 \%$ power. The largest number of order combinations in our counterbalancing was six. We 
therefore recruited 18 participants for each Group (i.e. lower limb CRPS, upper limb CRPS, lower limb controls, upper limb controls). One person with upper limb CRPS was not able to complete all the tasks, so we recruited an extra participant for this group (i.e. 19 people with upper limb CRPS). Therefore, 37 people with CRPS participated in the study ( $M$ age $=46.6, S D=12.5 ; 27$ female; 32 right-handed; see Tables $1 \& 2$ for clinical and demographic details). One person with left lower limb CRPS also had the left side of her torso affected. One person with CRPS in his left foot also had less severe CRPS in his left arm. One person with CRPS in her right hand also reported undiagnosed pain in her right foot, which she described as a "CRPS-like" sensation, although she did not show any signs of CRPS or experience any other symptoms of CRPS in this foot. All other participants with CRPS had only one limb affected. Sixteen of the people with CRPS also reported other pain diagnoses, such as fibromyalgia, that they considered less disabling or intrusive than their CRPS. Thirty-six painfree individuals ( $M$ age $=45.8, S D=13.7 ; 27$ female; 32 right-handed) took part as control participants.

\subsection{Protocol}

The protocol (see Fig. 1) was similar to that for our previous work examining the effect of experimentally induced pain on updating of bodily and spatial representations [83]. All participants provided informed written consent prior to undergoing a clinical assessment and completing selfreport questionnaires. They then completed hand temperature recordings and TDJs before and after interacting with tools (see Fig. 2). Broadly speaking, interactive tool-use consisted of two tasks, further detailed below: the CCT and a beanbag sorting task. Participants were debriefed and given the opportunity to ask questions at the end of the study. 


\subsubsection{Clinical assessment and self-report questionnaires}

We conducted a clinical assessment of CRPS symptoms on the affected limb and contralateral non-

affected limb. For control participants, we examined either their upper limbs or lower limbs, depending on where the patient that they were matched to had CRPS. When possible, we examined the same location as the person with CRPS. However, if the control participant was tested prior to the person with CRPS ( $n=11)$, or control participants were uncomfortable with using the CRPSaffected location for the person they were matched with (e.g. near the groin; $n=2$ ), we used the wrist or ankle as a proxy location. We visually assessed swelling, colour differences, and/or changes in hair and nail growth, and took photos of the most painful site and wrists/ankles in case there was any need for later verification/clarification of any of the clinical features. We used the figure of eight method to measure the swelling of ankles [60,76] or wrists [58]. We used a goniometer to quantify inversion, eversion, flexion, and extension of the ankle; or radial, ulnar, flexion, and extension of the wrist. We used a handheld infrared thermometer with an 8:1 distance to spot size ratio to measure the temperature of participants' most painful site and equivalent location on the contralateral limb, as well as their hands (dorsal and palmar surface of the thenar muscle), or ankles (flexor digitorum brevis). Seven pinprick stimulators (MRC Systems $\mathrm{GmbH}$, Germany), ranging from $8 \mathrm{mN}$ to $512 \mathrm{mN}$ in force, were used to measure Mechanical Pain Threshold. Mechanical Detection Threshold was measured using 20 Von Frey Filaments (BioSeb, France), ranging from $0.008 \mathrm{~g}$ to $300 \mathrm{~g}$ in force. An Exacta $^{\mathrm{TM}}$ two-point discriminator (North Coast Medical, USA) with pairs of rounded tips ranging from distances of $2 \mathrm{~mm}$ to $20 \mathrm{~mm}$ apart was used to assess Two Point Discrimination Threshold. Allodynia was assessed using a paintbrush, cotton buds, and cotton wool. We assessed Mechanical Detection Threshold, Mechanical Pain Threshold, and allodynia following the procedure of the German 
Research Network on Neuropathic Pain [65]. We assessed Two Point Discrimination Threshold on participants' middle finger pads. For the descriptive statistics, we expressed Mechanical Detection Threshold, Mechanical Pain Threshold, allodynia, and Two Point Discrimination Threshold as the difference between the two testing locations (i.e. affected/non-dominant, non-affected/dominant), by subtracting the scores from the non-affected side from the CRPS-affected side [65].

For all but eight participants with upper limb CRPS, the clinical assessment was performed the beginning of the research session. For the other eight participants, the clinical assessment was conducted in conjunction with a different study [24] in which they participated on the same day or within the 24 hours preceding the current study.

Following the clinical assessment, participants completed self-reported questionnaires. We used the Edinburgh Handedness Inventory (EHI [57]) to quantify hand dominance. EHI scores range from -100 to 100 , which reflect extreme left or right handedness, respectively. To characterise body perception, we used the Bath CRPS Body Perception Disturbance (BPD) scale [33]. The BPD has items about awareness of, attention to, emotional valance of, and desire to amputate the affected area, with higher scores suggesting a greater distortion in body perception (range 0 - 57). We used the Short-Form McGill Pain Questionnaire-2 (SF-MPQ-2) to assesses mean intensity of 22 pain descriptors [18]. A higher score on the SF-MPQ-2 indicates worse pain (range 0 - 10).

Because some changes in the perception of bodily and peripersonal space appear to resemble spatial attention deficits shown by patients with hemispatial neglect following stroke [31], participants were screened for visual, tactile, and motor neglect and/or extinction using confrontation tests (see supplemental digital content). We used unilateral or bilateral finger 
movements, light taps of the knee(s), or movements of the arm(s), to test visual, tactile, and motor domains, respectively. Tactile and motor neglect and/or extinction was examined with the participant's eyes open, and eyes closed. Any omissions on the confrontation tests were recorded.

\subsubsection{Hand temperature recordings}

We sought to replicate spatially defined hand temperature modulations (i.e., a reduction in hand temperature asymmetries for crossed, compared to uncrossed hands) that have previously been reported for people with upper limb CRPS [55]. Our main interest in replicating this effect was that we wanted to explore whether active tool-use could result in hand temperature modulations that were dependent on the position of the tools, not just the hands. That is, we aimed to explore whether crossing the tools after active tool use (and after bodily and spatial representations were updated) would result in similar spatially defined hand temperature modulations as crossing the hands. Such a finding would further support the notion that spatially defined modulation of hand temperature is dependent on the represented rather than actual location of the limbs [54]. Participants completed three sets of temperature recordings: two prior to tool-use, and one post tool-use. For all temperature recordings, participants were seated at a table with their head resting on a chin rest. Wireless thermometers (DS1992L Thermochron iButton ${ }^{\oplus}$, Maxim Integrated, San Jose, USA) were secured to a central point on the dorsal surface of each hand (CRPS-affected side/non-dominant, non-affected side/dominant) using microporous tape. The thermometers have been validated for skin temperature measurement [72,82]. They have also been used previously for similar research [10], and have comparable thermal resolution $\left(0.0625^{\circ} \mathrm{C}\right)$ to the thermal measures used to demonstrate spatially defined hand temperature modulations in CRPS [54,55]. The thermometers were programmed in OneWireViewer (version 0.3.19.47, Maxim Integrated, San Jose, USA). The flat, circular surface of the thermometers in contact with participants' skin had a diameter of $16 \mathrm{~mm}$. 
We made adjustments to the seating arrangement to accommodate people with CRPS when needed (e.g. using cushions, and/or keyboard wrist rests). During the temperature recordings, participant gave pain ratings every minute ( 8 per Arrangement, per Set), and were engaged in light conversation with the experimenter. The experimenter also monitored any hand movements via a computer feed from a camera placed in front of participants' hands, and he reminded participants to keep their hands still if they moved. There was no restriction on participants' gaze during the temperature recordings.

Across the entire study, hand temperature was recorded three times corresponding to three Effector Conditions [hands, t1 tools (pre tool-use), t2 tools (post tool-use)], each Condition consisting of two Arrangements (crossed, uncrossed). In the first Condition (hands), participants completed the temperature recording in two Arrangements (crossed, uncrossed) in a counterbalanced order. In the uncrossed Arrangement, participants positioned their hands straight in front of them, so they were aligned with their shoulders, and did not cross the body midline (e.g. the CRPS-affected hand would be located on the CRPS-affected side of space, and vice versa). In the crossed Arrangement, each hand crossed the body midline (e.g. so that the CRPS-affected hand would be located in the nonaffected side of space, and vice versa). These hand Arrangements replicated those used in previous studies to demonstrate spatially defined hand temperature changes [55]. Each hand Arrangement began with a two-minute rest period, after which we recorded the temperature from each thermometer every 12 seconds (i.e. $0.08 \mathrm{~Hz}$ ) for seven minutes, resulting in 36 temperature recordings for each hand in each Arrangement. We expected to see smaller hand temperature asymmetries for crossed compared to uncrossed hands for people with upper limb CRPS. We did not expect to see any spatially defined modulations of hand temperature asymmetries in the other two Groups (lower limb CRPS, controls). 
Once the temperature recordings for the two hand Arrangements were completed, we repeated the same procedure while manipulating the Arrangements (crossed, uncrossed) of the tools instead of the hands [i.e. the $t 1$ tools (pre tool-use) Condition]. Participants gripped tools that were in a crossed or an uncrossed Arrangement (order counterbalanced). Participants hands remained uncrossed (i.e. they did not cross the body midline) during both Tool Arrangement conditions. In the crossed Arrangement, only the tools crossed into the opposite side of space (e.g. the distal end of the left tool extending into the right side of space, and vice versa). The tools were propped up so that participants did not have to exert any effort keep the tools in position, and the experimenter moved the tools between the two Arrangements so that the participant was not required to actively use the tools.

Participants completed a final temperature recording block at the end of the study (i.e. t2 tools (post tool-use) Condition) whilst holding the tools in a crossed or uncrossed Arrangement following exactly the same methods as for the 11 tools condition. The same counterbalanced order of Arrangement (crossed, uncrossed) was repeated for all three Conditions (hand arrangement, t1 toolarrangement, $\mathrm{t} 2$ tool-arrangement) of temperature recording within each participant. For people with upper limb CRPS, we expected to see smaller hand temperature asymmetries for crossed compared to uncrossed tools after active tool-us (i.e. 2 tool-arrangement), if there was any influence of updating bodily and spatial representations on spatially defined modulations of CRPS symptoms. We did not expect to see any tool-use dependent effects on spatially defined modulations of hand temperature asymmetries in the other two Groups (lower limb CRPS, controls).

\subsubsection{Tactile Distance Judgements}


TDJs have been used to characterise changes in body representations following active tool-use (e.g. $[4,12,47,48])$. Participants made two Sets of TDJs for each Side of Body (affected/non-dominant, non-affected/dominant): once immediately before and once immediately after active tool-use. We used the same materials for the TDJs as for our previous study [83]. Two flat-ended circular rods (1 $\mathrm{mm}$ diameter) were attached to a bow compass to enable the experimenter to accurately adjust the distance between the two points. We administered the TDJs by applying the flat-ended circular rods to the radial side of participants' forearms (i.e. proximal-distally) while participants gripped the tools. The distance between the two rods was 4,6 , or $8 \mathrm{~cm}$. In each Set of TDJs, we applied each distance once in a randomised counterbalanced order. We blocked participants' vision of their stimulated arm with a cardboard box. Participants gave estimates of the perceived distance between the two felt points using a diagram with 22 lines of different lengths $(0.5 \mathrm{~cm}$ to $11.5 \mathrm{~cm}$, with $0.5 \mathrm{~cm}$ increments). In each Set, the TDJs were completed on both arms in a counterbalanced order. We expected that control participants would show a decrease in felt distance between two points, from pre to post tool-use, to indicate updating of body representation and a perceived reduction in arm length. We expected this effect to be smaller or absent in people with CRPS, which would indicate problems with updating.

\subsubsection{Tool-use: Crossmodal Congruency and Beanbag Sorting Tasks}

The Crossmodal Congruency task (CCT) was conducted with an adapted version of the materials and procedures used by Maravita and his colleagues [42]. This task has been widely used to measure changes in peripersonal space that arise from active tool-use $[36,44]$. There were four Sets of the CCT across the entire session: passive, active 1 , active 2 , and active 3 . In the active Sets, participants responded to vibrotactile stimuli originating from the handles of tools in the presence of visual distractors originating from the ends of the tools, crossing and uncrossing the tools every four trials. The passive Set was similar, but instead of the participants moving the tools, the experimenter 
moved the tools from the crossed to uncrossed Arrangement (or vice versa) half-way through the Set. The materials that we used for the CCT were from our previous study examining the effect of experimentally induced arm pain on updating of spatial and bodily representations in pain-free controls [83]. We used two aluminium tools that resembled golf clubs $(75 \mathrm{~cm}$ long, Fig. 2), with two red Light Emitting Diodes (LEDs) embedded in the 'blade' at the distal end of each tool. The handle of each tool was embedded with two electromagnetic solenoid-type stimulators (Tactor Minature Stimulators, Dancer Design, United Kingdom). A 4-channel amplifier (TactAmp 4.2, Dancer Design, United Kingdom) operated by Matlab 2014b (MathWorks) controlled the LEDs and the vibrotactile stimulators. Each tool had one LED and one vibrotactile stimulator positioned above the central axis of the tool, and one LED and one vibrotactile stimulator below it. Each tool had a wooden peg attached vertically in the 'blade'. To ensure that the distal ends of the tools always returned to the same position (e.g. after each time the tools were crossed or uncrossed), these pegs slotted into holes in a wooden board $(80 \times 100 \mathrm{~cm})$. The slots were $15 \mathrm{~cm}$ from the distal end of the board, and $15 \mathrm{~cm}$ left or right of the central axis of the board. Near the proximal ends of the tools there were gel wrist rests, which supported the tools and allowed participants to rest their hands.

\section{$* * *$ Fig. $2 * * *$}

During the CCT participants wore headphones that played white noise to mask the sound of the vibrotactile stimulators. They also rested their head on a chin rest to ensure a consistent head position. During the CCT, participants fixated on an off-white LED located at the same distance from the participant as the ends of the two tools, equally far from both tools and in line with participants' sagittal planes. The experimenter was seated behind participants and monitored their gaze on a computer feed delivered from a camera positioned $20 \mathrm{~cm}$ behind the end of the board, aligned with the chinrest and fixation LED. A second webcam was positioned directly below the first one and was 
angled such that participants' movement could be recorded during the CCT for offline evaluation of movement quality.

Each trial consisted of three 50 ms bursts of vibrotactile stimulation delivered to the thumb ("upper" location) or middle finger ("lower" location) of the left or right hand, separated by $50 \mathrm{~ms}$. Two participants with upper limb CRPS were unable to reach the vibrotactile stimulators with the middle finger of their affected side. Instead, one used the ring finger and the other her little finger. For each trial there were also three 50 ms flashes ("distractors") from the red LEDs at the ends of the tools. To maximise crossmodal interference the distractors preceded each vibrotactile stimulation by $30 \mathrm{~ms}$ [73]. Participants were required to indicate the location of the vibrotactile stimulation as quickly and accurately as possible, while ignoring the visual distractors. Participants' responses were collected with two triple switch foot pedals (Scythe, USA) with custom software. If participants' responses were incorrect or had latencies greater than $3000 \mathrm{~ms}$, all four LEDs flashed three times. Prior to starting the CCT, participants completed a practice set of 16 trials without moving the tools and in the uncrossed Arrangement. This practice set was designed to enable the participants to become accustomed to the task and its response format, and was repeated until the participant responded correctly on $>80 \%$ of trials.

Participants with upper-limb CRPS and their matched controls were asked to indicate the location of the vibrotactile stimulus using four-alternate forced-choice responses - left "upper" (thumb), left "lower" (finger), right "upper" (thumb), or right "lower" (finger) - by depressing the pedal under their left toe, left heel, right toe, or right heel, respectively. This protocol was altered from the CCT of Maravita and his colleagues [42], which used a two-alternate forced-choice response format (i.e. upper or lower, independent of body side). We added left/right judgements for people with upperlimb CRPS and their matched controls to enable us to examine for any arm-specific effects (e.g. any 
differences between responses for stimuli applied to the CRPS-affected/non-dominant versus nonaffected/dominant arm). This was also the response format we used in our previous study [83]. Pain and other CRPS symptoms prevented people with lower limb CRPS from using their affected limb to make foot pedal responses. Therefore, people with lower limb CRPS and their matched controls were asked to indicate the location of the vibrotactile stimulus using only two-alternate forced choice responses - "upper" (thumb) or "lower" (finger) - by depressing the pedal under the toe or heel of their non-affected foot, regardless of which hand (left or right) the stimulus had been presented to. The lower limb controls used the foot corresponding to that of the non-affected side of the person to whom they were matched.

The tools were Arranged in both crossed and uncrossed Arrangements during each Set of the CCT (passive, active 1, active 2, and active 3). The experimenter changed the Arrangement of the tools half-way through the first Set (passive), while participants kept hold of the handles. Thus, this Set did not involve any active tool-use by the participant. The order of the Tool Arrangements (crossed, uncrossed) was counterbalanced in this Set. For the three active Sets of the CCT, participants had to manoeuvre the tools to position them in the crossed or uncrossed position, alternating between the two Tool Arrangements every four trials. Participants were signalled to change the Tool Arrangement by all four LEDs illuminating. To maintain a consistent Arrangement of the tools across trials in the crossed condition, each tool was marked with a $5 \mathrm{~cm}$ wide blue band of tape, $30 \mathrm{~cm}$ from the 'blade' of the tool (i.e. the distal end), to indicate the locations at which participants should cross the tools (see Fig. 2).

Conventionally, updating of spatial representations is inferred from the CCT by comparing the effect of visual distractors on the speed and accuracy of detecting vibrotactile stimulation depending on the Tool Arrangement (crossed, uncrossed), the Visual field (same, opposite) in which the distractor 
was presented relative to the target, and the Congruence (congruent, incongruent) of the vertical elevation of the distractor relative to the target (e.g. both upper/lower, or one upper and one lower). Normal updating of peripersonal space representations [42] is considered to be indicated by 1) greater interference (i.e. longer RTs and/or higher error rates) from incongruent distractors in the same Visual Field as vibrotactile targets, compared to the opposite Visual Field, when the tools are uncrossed; and 2) greater interference from incongruent distractors when the distractors appear in the opposite Visual Field than the same Visual Field when the tools are crossed (because distractors in the opposite Visual Field appeared on the same tool as the vibrotactile targets). This combined pattern is taken to indicate that peripersonal space representations have been updated to incorporate the distal ends of the tools $[41,43]$. We expected the above pattern to be less pronounced in people with CRPS compared to controls, reflecting problems with updating of peripersonal space. Because these effects should develop as a function of active tool-use, we also considered how these effects developed over time by comparing performance across the four Sets.

Each Set of the CCT consisted of 96 trials. For the passive Set, participants completed 48 trials with the tools crossed or uncrossed (depending on the counterbalanced order) followed by 48 trials with the tools in the other Arrangement. For the active sets, participants completed all possible combinations of Tool Arrangement, Visual Field, and Congruence in a random order every 32 trials, three times per set. This resulted in a total of $384 \mathrm{CCT}$ trials across the entire session.

The changes in performance on the CCT are thought to depend on the active use of the tools. In the experiment of Maravita and his colleagues [42], having participants actively move the tools between the crossed and the uncrossed Arrangement was sufficient to generate such effects. Following pilot testing, we decided to incorporate a beanbag sorting task between each of the active Sets of the CCT (see Fig. 1) to amplify the desired effect. Thus, participants completed the beanbag sorting task 
twice: once between the first and second active CCT Set, and once between the second and third active CCT Set. The task was inspired by comparable research into active tool-use $[19,20,39]$, and required participants to sort and retrieve 12 distant beanbags, 11 times, with the same tools that were being used for the CCT. The beanbags had to be retrieved from the distal end of the board to coloured squares (see Fig. 2) on the left or right side of the board's proximal end, sorted by colour. This task lasted approximately 5 minutes. However, for some of the people with upper limb CRPS the task took longer, breaks were needed, and/or modifications to the task were made (e.g. placing the beanbags closer to the participants, or grasping the tools closer to their centre). If a participant required a break, they would continue to grasp the tools while the tools were supported by the gel wrist rests.

\subsubsection{Pain ratings}

In addition to the pain ratings that they gave during the temperature recordings, participants provided 12 pain ratings across all the sets of TDJs and sets of the CCT (see Fig. 1) so that their pain levels could be monitored during the experiment. Pain ratings were recorded before each Set of TDJs, before each tool Arrangement in the first ("passive") Set of the CCT, and before and after each subsequent "active" set of the CCT.

\subsubsection{Duration}

The entire session lasted approximately 4 hours for people with CRPS, and 3 hours for the matched controls. One person with upper limb CRPS was unable to complete the second beanbag sorting task and the final CCT Set due to a pain flare, but she was able to complete all the temperature recordings. Another person with upper limb CRPS could not undertake the temperature recordings, as her affected hand was covered by a lidocaine patch, but was able to complete the CCT and TDJs. 
Therefore, the final sample for each task comprised 36 people with CRPS: 18 people with upper limb CRPS, and 18 people with lower limb CRPS (see Tables 1 and 2 for clinical and demographic details). One person with lower limb CRPS had to split the session over two consecutive days due to pain and time constraints. One control participant's session was split over two days due to a power failure in the laboratory. For both participants who completed the study over two days, the first session ended after recording the temperature of their hands in a crossed or uncrossed position (i.e. prior to the temperature recordings with tools and any TJDs or active tool-use tasks). Temperature recordings from two control participants were excluded; one because they experienced a headache during the temperature recordings, which resolved for later parts of the study ( $M$ pain during the TDJs and $C C T<1 / 10$ ), and one because they fell asleep repeatedly during the temperature recordings. Both of these control participants' data were included for the CCT and TDJs.

\subsection{Analysis plan}

\subsubsection{Preliminary analyses}

We considered that motor impairments for people with upper limb CRPS might make it difficult to use tools, and therefore that any difficulties with updating bodily and spatial representation might be obscured by an individual's motor abilities. Therefore, we had a research assistant who was blind to the hypotheses of the study rate video recordings of participants' movement during the CCT and the beanbag sorting tasks. The research assistant gave a score from 1 (worst imaginable) to 10 (best imaginable) for the quality of the movement for each of the four recordings of each participant (i.e. CCT set $2 \&$ set 4 , beanbag sorting tasks $1 \& 2$ ). A mean score was calculated from the four ratings for each participant, which we compared with a one-way ANOVA with Group (upper limb CRPS, lower limb CRPS, control) as an independent variable. The research assistant was also asked to identify individuals who she suspected as having CRPS, and if so, which was the CRPS-affected limb (i.e. left or right upper or lower limb). 


\subsubsection{Tactile distance judgements analysis}

For participants' TDJs, we calculated a mean distance estimate for each Set (pre tool-use, post tooluse), and Side of Body (affected/non-dominant, non-affected/dominant). The TDJ distance estimates were analysed using a 2×2×2 ANOVA with Group (upper limb CRPS, lower limb CRPS, controls) as a between groups factor.

\subsubsection{Crossmodal congruency task analysis}

For the CCT, we performed separate ANOVAs for the upper limb and lower limb groups due to the differences in response format. The independent variables were Group (CRPS, controls), Set (passive, active 1, active 2, active 3), Tool Arrangement (crossed, uncrossed), and the Visual Field (same, opposite) that visual distractors appeared in relative to vibrotactile targets. For the upper limb CRPS group we also included the Side of Body (affected/non-dominant, non-affected/dominant) that received vibrotactile stimulation as an additional independent variable. We calculated the median RTs and percentage of errors within each level of each condition, after excluding trials with RTs $<200$ $\mathrm{ms}$ or $>3000 \mathrm{~ms}$ ( $1.08 \%$ of all trials). The median RTs were calculated from trials with correct responses only. To add clarity, we calculated the crossmodal interference by subtracting RTs, and error rates of congruent trials (i.e. where the visual distractors were vertically congruent with vibrotactile targets) from incongruent trials. We used crossmodal interference as the main dependent variable reported for the CCT.

We were primarily interested in interactions that involved Tool Arrangement and Visual Field for the CCT. Therefore, we do not report or elaborate on interactions that do not included Tool Arrangement and Visual Field because these are not of theoretical interest for our study. We also 
followed-up the interaction of Tool Arrangement and Visual field within each Group (upper or lower limb CRPS and their matched controls) on an a priori basis, because this interaction is most relevant for revealing tool-use dependent changes in peripersonal space representations. In the study by Maravita and his colleagues [36], changes in performance on the CCT due to active tool-use were only seen for RTs. Therefore, we only report CCT results derived from RTs (i.e. crossmodal interference) in the main article, although we report the analyses of accuracy on the CCT in the supplementary material (see supplemental digital content).

\subsubsection{Hand temperature analysis}

An average hand temperature was calculated from the 36 iButton recordings for each hand, Arrangement, and effector Condition. Because CRPS symptoms can manifest as the affected limb being physically warmer or cooler than the non-affected limb [26], we analysed absolute temperature asymmetries between the hands of the affected and the non-affected side of the body.

The absolute hand temperature asymmetries were analysed with two separate ANOVAs. First, we conducted a 3×2 ANOVA for the 'hands only' Effector Condition, with Group (upper limb CRPS, lower limb CRPS, controls), and Arrangement (crossed, uncrossed) as independent variables. We followedup this analysis with t-tests to compare the absolute hand temperature asymmetries for the crossed and uncrossed Arrangements in the hands only Effector Condition, within each Group. A difference in absolute hand temperature asymmetry between the crossed and uncrossed Arrangement for people with upper limb CRPS would indicate a spatially defined modulation of CRPS symptoms similar to that reported previously [54,55]. Second, to explore the effect of tool-use on spatially

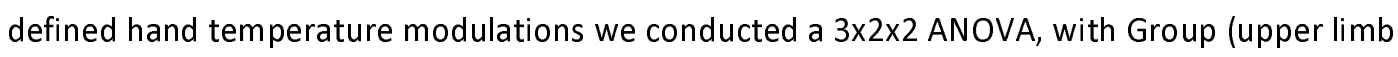
CRPS, lower limb CRPS, controls), Effector Condition (t1 tools, t2 tools), and Arrangement (crossed, uncrossed) as independent variables. We followed-up this analysis with separate $2 \times 2$ ANOVAs 
comparing absolute hand temperature asymmetries across Effector Condition (t1 tools, t2 tools) and tool Arrangements (crossed, uncrossed) within each Group.

\subsubsection{Inference criteria}

We considered a $p$-value $<.05$ as statistically significant. For all ANOVAs, Greenhouse-Geisser corrections were used when sphericity was not satisfied. Holm-Bonferroni corrections [28] were used for follow-up t-tests, and indicated by " $p_{\text {adjusted". See preregistration for a full list of planned }}$ analyses (https://osf.io/pjdw9).

\section{Results}

\subsection{Sensory Testing}

The descriptive statistics for the sensory testing are expressed as a relative difference, calculated by subtracting thresholds, or mean ratings for the non-affected/dominant arm from the affected/nondominant arm. For people with upper limb CRPS, the affected side relative to the non-affected side had a higher Mechanical Detection Threshold $(M=0.30 \mathrm{~g}, S D=0.81)$, lower Mechanical Pain Threshold $(M=-18.49 \mathrm{mN}, S D=79.41)$, more allodynia $(M$ pain rating from $0-100=22.51, S D=$ 27.04), and a lower Two Point Discrimination Threshold $(M=-0.03 \mathrm{~mm}, S D=0.97)$. This is consistent with signs of hypoesthesia, hyperalgesia, allodynia, and more precise tactile discrimination ability on the affected upper limb. However, the ratings were only significantly different from zero for allodynia, $t(17)=3.53, p=.015, d=1.71$. There was no significant difference for any of the thresholds from the other sensory measures for people with upper $\operatorname{limb} C R P S, t s(17) \leq 1.59, p s \geq$ $.188, d s \leq 0.77$. People with lower limb CRPS had a higher Mechanical Detection Threshold $(M=0.95$ g, $S D=2.80)$, lower Mechanical Pain Threshold $(M=-80.12 \mathrm{mN}, S D=280.33)$, more allodynia $(M$ pain rating from 0-100 $=36.41, S D=33.06)$, and a lower Two Point Discrimination Threshold $(M=-$ 
$0.09 \mathrm{~mm}, S D=1.21$ ) for their CRPS-affected area than the control site. This is consistent with signs of hypoesthesia, hyperalgesia, allodynia, and more precise tactile discrimination ability on the affected lower limb. However, the ratings were only significantly different from zero for allodynia, $t(14)=$ $4.13, p=.012, d=2.21$, not for any of the thresholds from the other sensory measures for people with lower $\operatorname{limb}$ CRPS, $t s(14) \leq 1.97, p s \geq .125, d s \leq 1.05$. The asymmetries of control participants' sensory ratings for Mechanical Detection Threshold $(M=0.04 \mathrm{~g}, S D=0.49)$, Mechanical Pain Threshold $(M=-6.65 \mathrm{mN}, S D=89.38)$, allodynia ( $M$ pain rating from $0-100=0.00, S D=0.00)$, and Two Point Discrimination $(M=0.06 \mathrm{~mm}, S D=0.95)$, were not significantly different from zero, $t \mathrm{~s}(35)$ $\leq 0.46, p s \geq .649, d s \leq 0.16$.

There was no evidence of neglect or extinction from the confrontation testing for controls, or for people with CRPS (see supplementary digital content).

\subsection{Quality of movement}

From the videos of participants' movements during tool-use, the research assistant correctly identified $35.3 \%$ of the people with upper limb CRPS as having an upper limb affected. They did not correctly identify any people with lower limb CRPS from their arm movements. There was a significant Group difference in the research assistant's ratings of participants' quality of movement during the CCT and beanbag sorting task, $F(2,58)=10.40, p<.001$, ? $^{2}{ }_{p}=.26$. This was driven by people with upper limb CRPS $(M=6.50, S D=1.20)$ being rated as having lower quality of movements than controls $(M=7.71, S D=0.68), t(46)=3.84, p_{\text {adjusted }}=.012, d=1.13$. There were no other differences in rated movement quality that were significant after correcting for multiple comparisons, $t s(42) \leq 1.35, p s_{\text {adjusted }} \geq .070, d s \leq 0.84$. These results suggest that people with upper limb CRPS had more difficulties with performing the tool-use tasks than the other two groups. 


\subsection{Tactile distance judgements}

The typical pattern taken to indicate that the body representation has been updated to accommodate the tools is a decrease in TDJs following active tool-use, which would be indicated by a main effect of Set. We did not observe this effect, nor any other main effects on TDJs when all groups were considered together, $F s(1,68) \leq 1.71, p s \geq .196$, $]^{2}{ }_{p} \leq .03$. There was, however, a 3-way interaction between Group, Set, and Side of Body on TDJs, $F(2,69)=4.37, p=.016$, ? $^{2}{ }_{p}=.11$ (Fig. 3). We followed-up this interaction with three two-way ANOVAs split by Group (i.e. controls, upper limb CRPS, and lower limb CRPS).

$* * *$ Fig. $3 * * *$

The follow-up analysis suggested that control participants did not update their body representation to facilitate tool-use, as there were no main effects or interactions for the analysis of control participants' TDJs, $F s(1,34) \leq 0.40, p s \geq .534$, $]^{2}{ }_{p} \leq .01$ (see supplemental digital content for full breakdown). In contrast, there was an interaction between Set and Side of Body for people with upper $\operatorname{limb} C R P S, F(1,17)=22.37, p<.001,]_{p}^{2}=.57$. There was no significant difference in TDJs for the affected $(M=9.28, S D=4.17)$ compared to non-affected $(M=10.20, S D=3.61)$ Side of Body pre tool-use, $t(17)=1.36, p_{\text {adjusted }}=.196, d=0.66$. However, post tool-use the TDJs were significantly smaller for the non-affected Side of Body $(M=8.48, S D=3.42)$ than the affected Side of Body $(M=$ $11.19, S D=3.87), t(17)=4.62, p_{\text {adjusted }}=.004, d=2.24$. Although the direct comparisons of pre vs post tool-use TDJs within each Side of Body were not significant after correcting for multiple comparisons, $t s(17) \leq 2.47, p s_{\text {adjusted }} \geq .084, d s \leq 1.20$, the observed pattern suggests that people with upper limb CRPS tended to update their body representation in the expected direction (i.e. a 
perceived lengthening) for their non-affected hand, and simultaneously in the opposite direction (i.e. a perceived shortening) for their affected hand.

For people with lower limb CRPS, the pattern of TDJs observed is qualitatively similar to that seen for people with upper limb CRPS (Fig. 3). That is, there was a numerical decrease in TDJs from pre to post tool-use for the arm on the non-affected side of the body (from $M=10.98, S D=5.09$; to $M=$ $9.65, S D=4.23$ ), and a numerical increase in TDJs for the arm on the affected side of the body (from $M=10.63, S D=4.90 ;$ to $M=10.98, S D=5.02)$. However, the interaction between Set and Side of Body did not reach statistical significance for this Group, $F(1,17)=3.23, p=.086$, $]_{p}^{2}=.16$.

\subsection{Crossmodal congruency task}

\subsubsection{People with upper limb CRPS and their matched controls}

A main effect of Group showed that people with upper limb CRPS experienced greater overall crossmodal interference $(M=65.23 \mathrm{~ms}, S D=37.59)$ than controls $(M=38.34 \mathrm{~ms}, S D=33.47), F(1$, $34)=5.14, p=.030,]_{p}^{2}=.13$. A main effect of Visual Field indicated that visual distractors appearing in the same Visual Field $(M=92.13 \mathrm{~ms}, S D=62.88)$ as vibrotactile targets resulted in greater crossmodal interference than those appearing in the opposite Visual Field $(M=11.44 \mathrm{~ms}, S D=$

53.64), $F(1,34)=28.56, p<.001,]_{p}^{2}=.46$. There were no other main effects on crossmodal interference for the analysis of upper limb patients and their matched controls, $F s(1,34) \leq 1.31, p s \geq$ .260,]_{\mathrm{p}}^{2} \leq .10$.

The critical interaction for indicating updating of peripersonal space was significant. That is, there was a significant interaction between Tool Arrangement and Visual Field, $F(1,34)=5.48, p=.025$, $]^{2}{ }_{p}$ $=.14$. There were no significant interactions involving Group, Tool Arrangement, and Visual field on 
crossmodal interference, $F_{S}(1,32) \leq 1.22, p s \geq .277$, $]_{p}^{2} \leq .09$. However, we analysed the Tool Arrangement by Visual Field interactions split by Group on an a priori basis (Fig. 4). There was no significant Tool Arrangement by Visual Field interaction for control participants, $F(1,17)=0.90, p=$ $.357, \mathrm{P}_{\mathrm{p}}^{2}=.05$. In contrast, there was a significant two-way interaction between Tool Arrangement and Visual Field for people with upper $\operatorname{limb}$ CRPS, $F(1,17)=5.18, p=.036,]^{2}{ }_{p}=.23$. The pattern of differences between conditions was consistent with an updating of peripersonal space representations. Specifically, there was significantly greater crossmodal interference for visual distractors appearing in the same $(M=119.18 \mathrm{~ms}, S D=88.24)$ compared to opposite $(M=-4.06 \mathrm{~ms}$, $S D=54.55)$ Visual Field, for uncrossed tools, $t(17)=6.54, p_{\text {adjusted }}=.004, d=3.1$. No other contrasts were significant after correcting for multiple comparisons, $t s(17) \leq 2.17, p \mathrm{~s}_{\text {adjusted }} \geq .231$, $d s \leq 1.05$. The overall pattern of crossmodal interference shown by the people with upper limb CRPS is consistent with updating of peripersonal space representations, as there is only a significant effect of Visual Field on crossmodal interference when the distractors in the same visual field appear on the same tool as vibrotactile targets (i.e. for uncrossed tools). When the tools are crossed, and so the distractors in the same Visual Field appear on the opposite tool, these distractors no longer significantly interfere with the processing of the vibrotactile target. This pattern of crossmodal interference are consistent with updating of peripersonal space representations, as it shows spacebased and object-based effects that would not be expected without the presence of tools. Our findings therefore suggest that people with upper limb CRPS updated their peripersonal space representations, but that their matched controls did not. There were no further interactions that involved Tool Arrangement and Visual Field (see supplemental digital content). 
In the lower limb group, a main effect of Group showed that people with lower limb CRPS experienced greater overall crossmodal interference $(M=110.01 \mathrm{~ms}, S D=60.63)$ than controls $(M=$ $67.89 \mathrm{~ms}, S D=41.07), F(1,34)=5.96, p=.020,]^{2}{ }_{\mathrm{p}}=.15$. There were no other significant main effects on crossmodal interference for the lower $\operatorname{limb}$ group, $F s(1,34) \leq 2.13, p s \geq .201$, $\left[{ }^{2} \leq .08\right.$.

The critical interaction for indicating updating of peripersonal space was significant, as there was an interaction between Tool Arrangement and Visual Field on crossmodal interference, $F(1,34)=8.80$, $p=.005,]_{\mathrm{p}}^{2}=.21$. There were no significant interactions involving Group, Tool Arrangement, and Visual Field, $F s(1,32) \leq 3.81, p s \geq .083$, ? $^{2}{ }_{p} \leq .09$. However, we analysed the Tool Arrangement by Visual Field interaction split by Group on an a priori basis (Fig. 5). Our findings were similar to those from the upper limb group, in that people with lower limb CRPS showed an interference pattern consistent with updating of peripersonal space representations, but their matched controls did not. There were no significant interactions involving Tool Arrangement and Visual Field on crossmodal interference for lower limb controls, $F s(1,32) \leq 0.81, p s \geq .380$, $]^{2}{ }_{p} \leq .16$. For people with lower limb CRPS, the interaction between Tool Arrangement and Visual Field on crossmodal interference was significant, $F(1,17)=9.93, p=.006,]_{p}^{2}=.37$. There was significantly greater crossmodal interference for uncrossed $(M=144.77 \mathrm{~ms}, S D=89.43)$ compared to crossed $(M=83.09 \mathrm{~ms}, S D=93.38)$ tools, for visual distractors appearing in the same Visual Field as the vibrotactile target, $t(17)=3.04, p_{\text {adjusted }}=$ $.048, d=1.47$. None of the other contrasts were significant after corrections for multiple comparisons, $t s(17) \leq 2.91, p s_{\text {adjusted }} \geq .072, d s \leq 1.41$. This suggests that visual distractors presented in the same Visual Field as the vibrotactile target interfered more only when they also appeared on the same tool as the vibrotactile target, which is consistent with updating of peripersonal space representations. Our results suggest that people with lower limb CRPS, but not their matched controls, updated their peripersonal space representations. There were no further interactions that involved Tool Arrangement and Visual Field (see supplemental digital content). 


\section{*** Fig. $5 * * *$}

\subsection{Hand temperature asymmetry}

\subsubsection{Hands Effector Condition}

Previous research has demonstrated a spatially defined modulation of hand temperature in which hand temperature asymmetry normalised when the hands were crossed [55]. The analysis of hand temperature asymmetry from the first Effector Condition (i.e. hands) revealed a main effect of Group , $F(2,67)=7.15, p=.002$, ( $^{2}{ }_{p}=.18$. This effect was driven by people with upper limb CRPS (M $\left.=1.12^{\circ} \mathrm{C}, S D=0.70\right)$ having greater absolute hand temperature asymmetries than both controls $(M=$ $\left.0.57{ }^{\circ} \mathrm{C}, S D=0.51\right), t(45)=2.96, p_{\text {adjusted }}=.027, d=0.88$, and people with lower limb CRPS $(M=0.58$ $\left.{ }^{\circ} \mathrm{C}, S D=0.41\right), t(34)=2.75, p_{\text {adjusted }}=.032, d=0.94$. There was no significant difference between absolute hand temperature asymmetries of people with lower limb CRPS compared to controls, $t(45)$ $=0.07, p_{\text {adjusted }}=.995, d=0.02$. There was no significant main effect of Arrangement, and no significant interaction of Group and Arrangement on hand temperature asymmetries from the hands only Condition, $F s(2,67) \leq 3.08$, ps $\geq .084$, $]_{p}^{2} \leq .04$. However, because the previous research showing spatially defined hand temperature modulations only examined people with upper limb CRPS [55], we followed-up the analyses of hand temperature from the hands only Condition, split by Group (upper limb CRPS, lower limb CRPS, controls; see Fig. 6). 
We did not find any evidence of spatially defined hand-temperate modulation in any groups. That is, there was no difference in absolute hand temperature asymmetries between crossed and uncrossed Arrangements for people with upper limb CRPS, $t(17)=0.37, p_{\text {adjusted }}=.336, d=0.18$, lower limb CRPS, $t(17)=1.40, p_{\text {adjusted }}=.711, d=0.68$, or controls, $t(28)=1.63, p_{\text {adjusted }}=.327, d=0.62$. Bayesian t-tests, computed using JASP software [77], revealed moderate evidence [84] that hand Arrangement had no effect on absolute hand temperature asymmetry for people with upper limb CRPS, $\mathrm{BF}_{10}=0.258$, and anecdotal evidence for no influence of hand Arrangement on hand temperature for people with lower limb CRPS, $\mathrm{BF}_{10}=0.558$, and for controls $\mathrm{BF}_{10}=0.766$. We considered whether these null effects for people with upper limb CRPS were because, unlike in previous studies examining spatial modulation of hand temperature [54,55], we did not pre-select only patients whose affected hand was at least $1{ }^{\circ} \mathrm{C}$ cooler than their non-affected hand. However, follow-up analyses of the data from only those people with upper limb CRPS whose affected hand was $\geq 1{ }^{\circ} \mathrm{C}$ cooler than their non-affected hand $(n=8)$ produced qualitatively similar results, $t(7)=$ $1.44, p=.194, d=0.51, \mathrm{BF}_{10}=0.724$. Overall, our findings suggest that CRPS symptoms (i.e. hand temperature asymmetry) were not modulated by the spatial location of the hands.

\subsubsection{Tools Effector Conditions}

Our main interest in examining spatial modulations of hand temperature asymmetries was to assess any effects that updating spatial representations might have on spatially defined hand temperature modulations. When all groups were considered together, there were no main effects of Group, Arrangement, or Effector Condition on hand temperature asymmetries measured in the tools conditions, $F s(1,67) \leq 2.86, p s \geq .095$, $]_{p}^{2} \leq .04$. There was, however, an interaction between Group and Tool Arrangement, $\mathrm{F}(2,67)=3.45, p=.038, \mathrm{\theta}_{\mathrm{p}}^{2}=.09$. This effects was driven by greater hand temperature asymmetries for uncrossed $\left(M=0.66^{\circ} \mathrm{C}, S D=0.46\right)$ than crossed $\left(M=0.48{ }^{\circ} \mathrm{C}, S D=\right.$ 0.41) tools for people with lower limb CRPS, although it was no longer significant after correcting for 
multiple comparisons, $t(17)=2.54, p_{\text {adjusted }}=.072, d=1.23$. There were no significant effects of Arrangement on hand temperature asymmetries for people with upper limb CRPS, or controls, ts $(17) \leq 0.65, p s_{\text {adjusted }}=1.000, d s \geq 0.25$. There were no other significant interactions, $F s(2,67) \leq 1.16$, ps $\geq .321, \mathrm{Q}_{\mathrm{p}}^{2} \leq .03$. In particular, there was no interaction between Group, Effector Condition, and Tool Arrangement to indicate any change in spatially defined hand temperature modulations after tool-use, $F(2,67)=1.16, p=.321,]_{\mathrm{p}}^{2}=.03$. Therefore, when all groups were considered, we did not find any evidence that active tool-use influenced hand temperature asymmetries. This was further supported by follow-up analyses split by group. That is, we analysed mean hand temperatures whilst holding the tools, for the two Tool Arrangements (crossed, uncrossed), before and after active tooluse (i.e. Effector Condition), split by Group (see supplemental digital content for descriptive statistics). There was no main effect of Tool Arrangement, nor were there any interactions involving Effector Condition or Tool Arrangement, on mean hand temperature asymmetry whilst holding tools for people with upper $\operatorname{limb} C R P S, F s(1,17) \leq 1.40, p s \geq .254$, $]_{p}^{2} \leq .08$, for people with lower limb $\operatorname{CRPS} F_{s}(1,17) \leq 2.62, p s \geq .124$, $]^{2}{ }_{p} \leq .13$, or for controls, $F s(1,28) \leq 2.10, p s \geq .158$, $]^{2}{ }_{p} \leq .07$. We therefore found no evidence suggesting that updating of spatial representations influences any spatially defined hand temperature modulation.

\subsection{Exploratory analyses}

There is evidence that the effects of tool-use on bodily and spatial representations can be lower for older than younger participants [16]. Because our participants are on average older than those in the previous studies upon which our methods are based, we explored age as a covariate for the analyses of the CCT and TDJs. Age was not a significant covariate for the key interactions of interest. That is, there were no significant interactions involving Age and Set on TDJs, $F s(1,69) \leq 1.63, p s \geq .205$, $]^{2}{ }_{p} \leq$ .02 , nor any other significant interactions involving Age. For the CCT there were no interactions involving Age, Tool Arrangement, and Visual Field that reached statistical significance, $F s(1,69) \leq$ 
$3.35, p s \geq .072,]^{2}{ }_{p} \leq .05$. This suggests that Age did not influence updating of bodily or spatial representations.

Next, we considered that our findings from the TDJs and CCT showing that people with upper limb CRPS updated bodily and spatial representations, but their matched controls did not, might be attributed to differences in movement. That is, they might be a consequence of people with upper limb CRPS having to exert more effort than controls to manoeuvre the tools, or by having to adapt their movement strategies to perform the task [66]. However, we did not find any evidence that the quality of movement was related to the updating of bodily or spatial representations for people with upper limb CRPS. That is, when we reanalysed the results using the research assistant's ratings of participants' quality of movement as a covariate we found that the covariate did not interact with Tool Arrangement and Visual Field in upper limb CRPS on the CCT, $F s(1,14) \leq 3.11, p s \geq .100$, $]_{p}^{2} \leq$ .30 , nor were there any interactions with the covariate involving Set or Side of the Body on the TDJs, $F(1,14)=0.05, p=.394,]_{p}^{2}=.05$. Due to low sample sizes we were not able to make direct comparisons between people who the research assistant correctly identified as having upper limb CRPS based on their movement $(n=6)$, and those who had had an upper limb affected but were not identified $(n=11)$. Nonetheless, this analysis provides no indication that the effort exerted or the way people moved were related to the updating of bodily and spatial representations.

\section{Discussion}

Our study was the first to examine the updating of body and peripersonal space representations of individuals with CRPS following tool-use. In upper limb CRPS, tactile distance judgements (TDJs) were not significantly different between arms pre tool-use, but were significantly greater for the CRPSaffected arm than the non-affected arm post tool-use. This is consistent with the perceived 
lengthening of the non-affected arm that is typically shown by pain-free controls, and/or a perceived shortening of the affected arm. People with lower limb CRPS showed similar (albeit non-significant) changes to the upper limb patients on TDJs. Contrary to our predictions, we found that both groups of people with CRPS showed patterns of crossmodal interference on the CCT indicative of an updating of peripersonal space that were more pronounced than the controls in this study, as the controls showed no evidence of updating. Overall, our findings suggest that people with CRPS have more malleable bodily and spatial representations than controls.

Our control participants did not show the expected updating of bodily and spatial representations, as seen in previous research (e.g. $[4,12,42,47,48,83])$. This could be because our sample was, on average, older than the typical student samples previously used (e.g. $[12,42,48,83])$, and older age is associated with lower flexibility of such representations during and following tool-use [16]. It is therefore particularly noteworthy that participants with CRPS showed updating of body and peripersonal space representations, although their matched controls did not.

Consistent with previous research (e.g. $[9,32,34,51,81]$ ) we found that participants with CRPS had distorted representations of their affected limbs. Tajadura-Jiménez and her colleagues recently showed that people with CRPS are able to update their bodily representations, because manipulating the frequency of auditory feedback during walking changed the perceived dimensions of the CRPS-affected limb [75]. However, they did not directly compare the performance of the people with CRPS to controls, meaning it is unclear from their results if the extent of this updating was normal. Our study is the first to show that the ability to update bodily representations is different in people with CRPS relative to pain-free controls, and might differ for the affected and non-affected side of the body. 
The difference in updating for the affected and non-affected side of the body is suggested by the changes in TDJs for the upper limb CRPS group. These were consistent with a perceived lengthening of the non-affected arm to facilitate the tools (i.e. the expected change following tool-use) and a perceived shortening of the affected arm, resulting in a significant difference in TDJs for the two arms after tool-use. We observed a numerically similar, though non-significant, pattern for people with lower limb CRPS. A perceived shrinking of the arm, measured by forearm bisection, has been observed after pain-free participants performed tool-use tasks by using proximal body parts (i.e. shoulder), whereas using distal ones (i.e. wrist) resulted in perceived lengthening [66]. Our results might therefore be explained by people with upper limb CRPS using proximal movements in their affected arm to perform the tool-use tasks in order to protect painful distal parts of the arm. However, fewer than half of the people with upper limb CRPS had their pain and other symptoms limited to only a distal part of the arm, and we did not find any effect of the rated quality of participants' movement on the TDJs for upper limb CRPS. Alternatively, our results could reflect a tendency to avoid movement of the CRPS-affected limb in everyday life. Distorted bodily and spatial representations are common following limb immobilisation [4,25,35], but quickly normalize once movement is regained [3]. Limited movement of the affected limb has been suggested to cause distorted bodily and spatial representations in CRPS [61]. Since most of our participants reported their limb as seeming larger than reality, our findings could therefore reflect a normalisation of the body representation for the CRPS-affected limb during the tool-use task due to the execution of movements that are normally avoided.

We observed a body-side specific trend when testing the arms of people with lower limb CRPS that was similar to the significant pattern we found in upper limb patients. Although we can only interpret this trend with caution, if it were found to be significant (e.g. in a larger sample), then it 
would provide further support for the idea that the differences in updating that we observed cannot be attributed to peripheral changes, but instead implicate central mechanisms. Neurological assessments and neuroimaging have suggested the presence of parietal lobe dysfunction in CRPS ([15,37]; for review see [29]). For instance, motor impairments in CRPS correlate with posterior parietal cortex activation [37], an area that is important for sensorimotor integration [87] and maintaining a representation of the state of the body [70]. Our finding showing altered updating the representations of the CRPS-affected limb in upper limb patients, is also consistent with altered parietal lobe functioning.

We expected people with CRPS to have less malleable spatial representations than controls, as their flexibility is use dependent [71], and many people with CRPS avoid moving their affected limb [61]. Yet the results from the CCT suggest the opposite for both upper and lower limb CRPS patients. De Vignemont and lannetti [17] have proposed that peripersonal space is comprised of distinct goaldirected and defensive representations that serve to facilitate action and self-protection, respectively. Many participants with lower limb CRPS used walking aids, which might facilitate updating of goal-directed peripersonal space representations, and could potentially explain the greater flexibility of these representations that we observed $[22,71]$. However, this cannot be said for the upper limb sample, as a majority presented with motor deficits that would likely interfere with daily tool-use. It is possible that our findings instead reflect a greater activation of defensive representations by people with CRPS to avoid painful encounters. The dimensions of defensive peripersonal space representations have yet to be mapped in CRPS. However, enlarged representations, as measured by the hand-blink reflex, have been found in people with trigeminal neuralgia [7]. Although the tool-use tasks in our study are typically considered goal-directed, it is possible that the updating seen reflects engagement of defensive peripersonal space in upper limb CRPS, as the tasks were painful. This is consistent with our finding that people with CRPS 
experienced greater crossmodal interference than controls. Engaging defensive representations would facilitate multisensory integration, a key feature of peripersonal space [69]. Our findings therefore highlight ways in which spatial representations might differ in CRPS.

Contrary to our predictions, we found no evidence that spatially defined hand temperature modulations were further altered by active tool-use. This is not surprising given that we also did not observe any spatially defined modulation of hand temperature before tool-use, when only hand Arrangement was manipulated, despite having a larger sample size than previous studies reporting such an effect $[54,55]$. We measured hand temperature for the same or similar time-period to previous studies $[54,55]$. Although we used different equipment to measure temperature than used in previous studies, this equipment (the iButton) has sufficient sensitivity to detect effects of the magnitudes previously reported [72,82], and has been used to demonstrate spatially-modulated changes in hand temperature of healthy individuals [10]. Our finding of no spatially defined modulation of CRPS symptoms is therefore unlikely to be due to methodological limitations.

Distorted bodily and spatial representations could contribute to the maintenance of CRPS by distorting motor predictions. The sensorimotor theory of pain [27] postulates that an incongruence between motor predictions and sensory feedback could underpin some pathological pain conditions, and has been proposed as an explanation for CRPS [45]. Our findings suggest that bodily and spatial representations are more flexible and perhaps less stable in CRPS than controls. Less stable and/or reliable representations might compromise motor predictions by increasing noise in the sensorimotor system [86], thereby increasing the likelihood of sensorimotor incongruence. Altered updating of bodily and spatial representations in people with CRPS is unlikely to be due to the acute experience of pain, as we have previously shown that capsaicin-induced pain in normally pain-free participants does not alter updating of bodily and spatial representations [83]. Although, a chronic 
experience of pain, and/or altered sensory processing [2] might give rise to our results. These findings could implicate central mechanisms in CRPS $[15,29,63]$, as the representations of the body and peripersonal space both rely on processing in the parietal cortex $[5,69,78]$, and less stable representations could result in sensorimotor incongruences.

To conclude, our study was the first to examine how body and peripersonal space representations are updated in people with CRPS compared to controls. Our findings suggest that people with CRPS have less stable representations of the body and peripersonal space, and point toward alterations in neuropsychological processing that are specific to the affected body-side rather than selective for the CRPS-affected limb. Although we did not replicate previously reported spatially defined modulations of CRPS symptoms, our findings demonstrate that bodily and spatial processing is altered in a manner consistent with existing theories of how chronic pain might arise in the absence of clear tissue pathology.

\section{Conflict of interest}

The authors have no conflicts of interest to declare.

\section{Acknowledgements}

We would like to thank Ms Ottilie Kuehne and Ms Josephine Pedder for their help with the study.

ADV received funding from the GW4 Medical Research Council BioMed Doctoral Training

Partnership (1793344). The funders had no role in study design, data collection and analysis, decision to publish, or preparation of the manuscript. 


\section{References}

[1] Bailey J, Nelson S, Lewis JS, McCabe CS. Imaging and clinical evidence of sensorimotor problems in CRPS: utilizing novel treatment approaches. J Neuroimmune Pharmacol 2013;8(3):564575.

[2] Bar-Shalita T, Livshitz A, Levin-Meltz Y, Rand D, Deutsch L, Vatine J-J. Sensory modulation dysfunction is associated with Complex Regional Pain Syndrome. PloS one $2018 ; 13(8): e 0201354$.

[3] Bassolino M, Bove M, Jacono M, Fadiga L, Pozzo T. Functional effect of short-term immobilization: kinematic changes and recovery on reaching-to-grasp. Neuroscience $2012 ; 215: 127-134$.

[4] Bassolino M, Finisguerra A, Canzoneri E, Serino A, Pozzo T. Dissociating effect of upper limb nonuse and overuse on space and body representations. Neuropsychologia 2015;70:385-392.

[5] Blanke O. Multisensory brain mechanisms of bodily self-consciousness. Nat Rev Neurosci 2012;13(8):556-571.

[6] Boesch E, Bellan V, Moseley GL, Stanton TR. The effect of bodily illusions on clinical pain: a systematic review and meta-analysis. Pain 2016;157(3):516-529.

[7] Bufacchi R, Sambo C, Di Stefano G, Cruccu G, lannetti G. Pain outside the body: defensive peripersonal space deformation in trigeminal neuralgia. Scientific reports $2017 ; 7(1): 12487$.

[8] Bultitude JH, Rafal RD. Derangement of body representation in complex regional pain syndrome: report of a case treated with mirror and prisms. Exp Brain Res 2010;204(3):409-418.

[9] Bultitude JH, Walker I, Spence C. Space-based bias of covert visual attention in complex regional pain syndrome. Brain 2017.

[10] Calzolari E, Gallace A, Moseley GL, Vallar G. Effect of prism adaptation on thermoregulatory control in humans. Behavioural Brain Research 2016;296:339-350. 
[11] Canzoneri E, Marzolla M, Amoresano A, Verni G, Serino A. Amputation and prosthesis implantation shape body and peripersonal space representations. Scientific reports 2013;3:2844.

[12] Canzoneri E, Ubaldi S, Rastelli V, Finisguerra A, Bassolino M, Serino A. Tool-use reshapes the boundaries of body and peripersonal space representations. Experimental Brain Research 2013;228(1):25-42.

[13] Cardinali L, Jacobs S, Brozzoli C, Frassinetti F, Roy AC, Farnè A. Grab an object with a tool and change your body: tool-use-dependent changes of body representation for action. Experimental Brain Research 2012;218(2):259-271.

[14] Christophe L, Chabanat E, Delporte L, Revol P, Volckmann P, Jacquin-Courtois S, Rossetti Y. Prisms to Shift Pain Away: Pathophysiological and Therapeutic Exploration of CRPS with Prism Adaptation. Neural Plasticity 2016:21.

[15] Cohen H, McCabe CS, Harris N, Hall J, Lewis JS, Blake DR. Clinical evidence of parietal cortex dysfunction and correlation with extent of allodynia in CRPS type 1. Eur J Pain 2013;17(4):527-538.

[16] Costello MC, Bloesch EK, Davoli CC, Panting ND, Abrams RA, Brockmole JR. Spatial representations in older adults are not modified by action: Evidence from tool use. Psychology and aging 2015;30(3):656.

[17] De Vignemont F, lannetti GD. How many peripersonal spaces? Neuropsychologia 2015;70:327334.

[18] Dworkin RH, Turk DC, Revicki DA, Harding G, Coyne KS, Peirce-Sandner S, Bhagwat D, Everton D, Burke LB, Cowan P. Development and initial validation of an expanded and revised version of the Short-form McGill Pain Questionnaire (SF-MPQ-2). PAIN ${ }^{\circledast 2}$ 2009;144(1-2):35-42.

[19] Farnè A, Iriki A, Làdavas E. Shaping multisensory action-space with tools: evidence from patients with cross-modal extinction. Neuropsychologia 2005;43(2):238-248. 
[20] Farnè A, Làdavas E. Dynamic size-change of hand peripersonal space following tool use.

Neuroreport 2000;11(8):1645-1649.

[21] Filbrich L, Alamia A, Verfaille C, Berquin A, Barbier O, Libouton X, Fraselle V, Mouraux D, Legrain V. Biased visuospatial perception in complex regional pain syndrome. Scientific reports 2017;7(1):9712.

[22] Galli G, Noel JP, Canzoneri E, Blanke O, Serino A. The wheelchair as a full-body tool extending the peripersonal space. Frontiers in psychology 2015;6:639.

[23] Haggard P, lannetti GD, Longo MR. Spatial sensory organization and body representation in pain perception. Current Biology 2013;23(4):R164-R176.

[24] Halicka M, Vitters $\varnothing$ AD, Proulx MJ, Bultitude JH. Pain Reduction by Inducing Sensory-Motor Adaptation in Complex Regional Pain Syndrome (CRPS PRISMA): Protocol for a Double-blind Randomized Controlled Trial. medRxiv 2019:19000653.

[25] Hall J, Llewellyn A, Palmer S, Rowett-Harris J, Atkins RM, McCabe CS. Sensorimotor dysfunction after limb fracture-An exploratory study. European Journal of Pain 2016;20(9):1402-1412.

[26] Harden RN, Bruehl S, Stanton-Hicks M, Wilson PR. Proposed new diagnostic criteria for complex regional pain syndrome. Pain medicine 2007;8(4):326-331.

[27] Harris AJ. Cortical origin of pathological pain. Lancet 1999;354(9188):1464-1466.

[28] Holm S. A simple sequentially rejective multiple test procedure. Scandinavian journal of statistics 1979:65-70.

[29] Kuttikat A, Noreika V, Shenker N, Chennu S, Bekinschtein T, Brown CA. Neurocognitive and neuroplastic mechanisms of novel clinical signs in CRPS. Frontiers in human neuroscience 2016;10:16.

[30] Lee H, Lamb SE, Bagg MK, Toomey E, Cashin AG, Moseley GL. Reproducible and replicable pain research: a critical review. Pain 2018;159(9):1683-1689.

[31] Legrain V, Bultitude JH, De Paepe AL, Rossetti Y. Pain, body, and space: what do patients with complex regional pain syndrome really neglect? Pain 2012;153(5):948-951. 
[32] Lewis JS, Kersten P, McCabe CS, McPherson KM, Blake DR. Body perception disturbance: a contribution to pain in complex regional pain syndrome (CRPS). PAIN ${ }^{\circledR} 2007 ; 133(1): 111-119$.

[33] Lewis JS, McCabe CS. Body perception disturbance (BPD) in CRPS. Practical Pain Management 2010:60-66.

[34] Lewis JS, Schweinhardt P. Perceptions of the painful body: the relationship between body perception disturbance, pain and tactile discrimination in complex regional pain syndrome. European Journal of Pain 2012;16(9):1320-1330.

[35] Lissek S, Wilimzig C, Stude P, Pleger B, Kalisch T, Maier C, Peters SA, Nicolas V, Tegenthoff M, Dinse HR. Immobilization impairs tactile perception and shrinks somatosensory cortical maps. Current Biology 2009;19(10):837-842.

[36] Macaluso E, Maravita A. The representation of space near the body through touch and vision. Neuropsychologia 2010;48(3):782-795.

[37] Maihöfner C, Baron R, DeCol R, Binder A, Birklein F, Deuschl G, Handwerker HO, Schattschneider J. The motor system shows adaptive changes in complex regional pain syndrome. Brain 2007;130(10):2671-2687.

[38] Makin TR, Wilf M, Schwartz I, Zohary E. Amputees "neglect" the space near their missing hand. Psychological science 2010;21(1):55-57.

[39] Maravita A, Clarke K, Husain M, Driver J. Active tool use with the contralesional hand can reduce cross-modal extinction of touch on that hand. Neurocase 2002;8(6):411-416.

[40] Maravita A, Iriki A. Tools for the body (schema). Trends in cognitive sciences 2004;8(2):79-86.

[41] Maravita A, Spence C, Driver J. Multisensory integration and the body schema: close to hand and within reach. Current biology 2003;13(13):R531-R539.

[42] Maravita A, Spence C, Kennett S, Driver J. Tool-use changes multimodal spatial interactions between vision and touch in normal humans. Cognition 2002;83(2):25-34. 
[43] Marini F, Romano D, Maravita A. The contribution of response conflict, multisensory integration, and body-mediated attention to the crossmodal congruency effect. Experimental brain research 2017;235(3):873-887.

[44] Martel M, Cardinali L, Roy AC, Farnè A. Tool-use: An open window into body representation and its plasticity. Cognitive neuropsychology 2016;33(1-2):82-101.

[45] McCabe CS, Blake DR. Evidence for a mismatch between the brain's movement control system and sensory system as an explanation for some pain-related disorders. Current pain and headache reports 2007;11(2):104-108.

[46] Medina J, Coslett HB. From maps to form to space: Touch and the body schema. Neuropsychologia 2010;48(3):645-654.

[47] Miller LE, Longo MR, Saygin AP. Tool morphology constrains the effects of tool use on body representations. Journal of Experimental Psychology: Human Perception and Performance 2014;40(6):2143.

[48] Miller LE, Longo MR, Saygin AP. Visual illusion of tool use recalibrates tactile perception. Cognition 2017;162:32-40.

[49] Miller LE, Montroni L, Koun E, Salemme R, Hayward V, Farnè A. Sensing with tools extends somatosensory processing beyond the body. Nature 2018;561(7722):239.

[50] Moseley GL. Graded motor imagery is effective for long-standing complex regional pain syndrome: a randomised controlled trial. Pain 2004;108(1-2):192-198.

[51] Moseley GL. Distorted body image in complex regional pain syndrome. Neurology $2005 ; 65(5): 773$.

[52] Moseley GL. Is successful rehabilitation of complex regional pain syndrome due to sustained attention to the affected limb? A randomised clinical trial. Pain 2005;114(1-2):54-61.

[53] Moseley GL. Graded motor imagery for pathologic pain: a randomized controlled trial. Neurology 2006;67(12):2129-2134. 
[54] Moseley GL, Gallace A, Di Pietro F, Spence C, lannetti GD. Limb-specific autonomic dysfunction in complex regional pain syndrome modulated by wearing prism glasses. Pain 2013;154(11):2463-2468.

[55] Moseley GL, Gallace A, lannetti GD. Spatially defined modulation of skin temperature and hand ownership of both hands in patients with unilateral complex regional pain syndrome. Brain 2012;135(12):3676-3686.

[56] Moseley GL, Gallace A, Spence C. Space-based, but not arm-based, shift in tactile processing in complex regional pain syndrome and its relationship to cooling of the affected limb. Brain 2009;132(Pt 11):3142-3151.

[57] Oldfield RC. The assessment and analysis of handedness: the Edinburgh inventory. Neuropsychologia 1971;9(1):97-113.

[58] Pellecchia GL. Figure-of-eight method of measuring hand size:: reliability and concurrent validity. Journal of hand therapy 2003;16(4):300-304.

[59] Peltz E, Seifert F, Lanz S, Müller R, Maihöfner C. Impaired hand size estimation in CRPS. The Journal of Pain 2011;12(10):1095-1101.

[60] Petersen EJ, Irish SM, Lyons CL, Miklaski SF, Bryan JM, Henderson NE, Masullo LN. Reliability of water volumetry and the figure of eight method on subjects with ankle joint swelling. Journal of Orthopaedic \& Sports Physical Therapy 1999;29(10):609-615.

[61] Punt DT, Cooper L, Hey M, Johnson MI. Neglect-like symptoms in complex regional pain syndrome: learned nonuse by another name? Pain 2013;154(2):200-203.

[62] Reid E, Wallwork SB, Harvie D, Chalmers KJ, Gallace A, Spence C, Moseley GL. A new kind of spatial inattention associated with chronic limb pain? Annals of neurology 2016;79(4):701704.

[63] Reinersmann A, Maier C, Schwenkreis P, Lenz M. Complex regional pain syndrome: more than a peripheral disease. Pain management 2013;3(6):495-502 . 
[64] Rizzolatti G, Fadiga L, Fogassi L, Gallese V. The space around us. Science 1997;277(5323):190-

191.

[65] Rolke R, Magerl W, Campbell KA, Schalber C, Caspari S, Birklein F, Treede R-D. Quantitative sensory testing: a comprehensive protocol for clinical trials. European journal of pain 2006;10(1):77-88.

[66] Romano D, Uberti E, Caggiano P, Cocchini G, Maravita A. Different tool training induces specific effects on body metric representation. Experimental Brain Research 2019;237(2):493-501.

[67] Schwoebel J, Friedman R, Duda N, Coslett HB. Pain and the body schema: evidence for peripheral effects on mental representations of movement. Brain 2001;124(Pt 10):20982104.

[68] Senkowski D, Heinz A. Chronic pain and distorted body image: Implications for multisensory feedback interventions. Neurosci Biobehav Rev 2016;69:252-259.

[69] Serino A. Peripersonal space (PPS) as a multisensory interface between the individual and the environment, defining the space of the self. Neuroscience \& Biobehavioral Reviews 2019.

[70] Serino A, Alsmith A, Costantini M, Mandrigin A, Tajadura-Jimenez A, Lopez C. Bodily ownership and self-location: components of bodily self-consciousness. Consciousness and cognition 2013;22(4):1239-1252.

[71] Serino A, Bassolino M, Farne A, Ladavas E. Extended multisensory space in blind cane users. Psychological science 2007;18(7):642-648.

[72] Smith AH, Crabtree D, Bilzon J, Walsh N. The validity of wireless iButtons ${ }^{\oplus}$ and thermistors for human skin temperature measurement. Physiological measurement 2009;31(1):95.

[73] Spence C, Pavani F, Maravita A, Holmes N. Multisensory contributions to the 3-D representation of visuotactile peripersonal space in humans: evidence from the crossmodal congruency task. Journal of Physiology-Paris 2004;98(1):171-189.

[74] Sumitani M, Rossetti Y, Shibata M, Matsuda Y, Sakaue G, Inoue T, Mashimo T, Miyauchi S. Prism adaptation to optical deviation alleviates pathologic pain. Neurology 2007;68(2):128-133. 
[75] Tajadura-Jiménez A, Cohen H, Bianchi-Berthouze N. Bodily sensory inputs and anomalous bodily experiences in complex regional pain syndrome: Evaluation of the potential effects of sound feedback. Frontiers in human neuroscience 2017;11:379.

[76] Tatro-Adams D, McGann SF, Carbone W. Reliability of the figure-of-eight method of ankle measurement. Journal of Orthopaedic \& Sports Physical Therapy 1995;22(4):161-163.

[77] Team J. JASP (Version 0.9), 2018.

[78] Tsakiris M. My body in the brain: a neurocognitive model of body-ownership. Neuropsychologia 2010;48(3):703-712.

[79] Tsay AJ, Allen T, Proske U, Giummarra MJ. Sensing the body in chronic pain: a review of psychophysical studies implicating altered body representation. Neuroscience \& Biobehavioral Reviews 2015;52:221-232.

[80] Tseng H-H, Bossong MG, Modinos G, Chen K-M, McGuire P, Allen P. A systematic review of multisensory cognitive-affective integration in schizophrenia. Neuroscience \& Biobehavioral Reviews 2015;55:444-452.

[81] Turton A, Palmer M, Grieve S, Moss T, Lewis JS, McCabe CS. Evaluation of a prototype tool for communicating body perception disturbances in complex regional pain syndrome. Frontiers in human neuroscience 2013;7:517.

[82] van Marken Lichtenbelt WD, Daanen HA, Wouters L, Fronczek R, Raymann RJ, Severens NM, Van Someren EJ. Evaluation of wireless determination of skin temperature using iButtons. Physiology \& behavior 2006;88(4-5):489-497.

[83] Vitters $\varnothing A D$, Halicka M, Buckingham G, Proulx MJ, Bultitude JH. Experimentally induced pain does not influence updating of peripersonal space and body representations following tooluse. PloS one 2019;14(5):e0210045.

[84] Wagenmakers EJ, Love J, Marsman M, Jamil T, Ly A, Verhagen J, Selker R, Gronau QF, Dropmann D, Boutin B, Meerhoff F, Knight P, Raj A, van Kesteren EJ, van Doorn J, Smira M, Epskamp S, Etz A, Matzke D, de Jong T, van den Bergh D, Sarafoglou A, Steingroever H, Derks K, Rouder 
JN, Morey RD. Bayesian inference for psychology. Part II: Example applications with JASP.

Psychon Bull Rev 2018;25(1):58-76.

[85] Wittayer M, Dimova V, Birklein F, Schlereth T. Correlates and importance of neglect-like symptoms in complex regional pain syndrome. Pain 2018;159(5):978-986.

[86] Wolpert DM, Diedrichsen J, Flanagan JR. Principles of sensorimotor learning. Nature Reviews Neuroscience 2011;12(12):739.

[87] Wolpert DM, Goodbody SJ, Husain M. Maintaining internal representations: the role of the human superior parietal lobe. Nature neuroscience 1998;1(6):529. 


\section{Table 1}

Clinical and demographic information for participants with upper limb CRPS.

Table 2

Clinical and demographic information for participants with lower limb CRPS.

Fig. 1

The study's procedure is outlined. For the first set of temperature recordings (red boxes), the participant's hand's temperature were recorded from their hands whilst the hands rested in a crossed and an uncrossed Arrangement. For the second set of temperature recordings, the temperatures were recorded with the hands uncrossed whilst holding the tools in a crossed and an uncrossed Arrangement. For the final temperature recordings we only measured hand temperature for the two tool Arrangements (tools crossed, tools uncrossed). The same counterbalancing order was used for the order of hand/tool Arrangement conditions for all the temperature recording Sets. Tactile Distance Judgements (TDJs; green boxes) were performed on the affected and non-affected arms (order counterbalanced), pre and post active tool-use. The experimenter changed the tools between the crossed and uncrossed Arrangements during the passive stage of the Crossmodal Congruency task (CCT; green boxes), in a counterbalanced order. During the active stages of the CCT (active 1, active 2, active 3), participants changed the tool Arrangement (crossed, uncrossed) by manoeuvring the tools themselves (see Fig. 2). The beanbag sorting task involved retrieving and sorting 12 beanbags, using the same tools that were used for the CCT (see Fig. 2). All tasks that involved active tool-use are depicted with shaded boxes (i.e. CCT sets 2-4, and beanbag sorting tasks). The blue vertical arrows indicate timings of pain ratings that were recorded before, during, 
and/or after the TDJs and CCT. In addition, participants gave 8 pain ratings for each Arrangement, during each set of temperature recording Sets.

Fig. 2

Tools used for the Crossmodal Congruency and Beanbag Sorting Tasks. The tools are depicted in their uncrossed (a), and crossed (b) Arrangements. The close-up of the distal end of a tool (c) shows the location of two red Light Emitting Diodes (LEDs) embedded in the 'blades' of the tools, which also had a vertical peg attached (white oval) that slotted into holes in the wooden board. The pegs ensured the positions of the distal ends of the tools were consistent for crossed and uncrossed trials. The blue lines midway along the tools' shaft indicated the location at which the tools should be crossed (b). Vibrotactile stimulators were embedded in the handles of the tools. A fixation light (offwhite LED) was positioned mid-way between the ends of the tools, in line with the participant's sagittal plane. A webcam was placed beyond the distal ends of the tools, also aligned with participant's sagittal plane. Fig 2. is reused with permission (CC BY 4.0) from Vittersø et al. [83].

Fig. 3

Results for the Tactile Distance Judgement (TDJ) task. The perceived distance between two points placed on participants' forearms (TDJs) are depicted, split by Group (upper limb CRPS [ $n=18$ ], lower limb CRPS [ $=18$ ], controls [ $n=35]$ ), Side of Body (affected/non-dominant, nonaffected/dominant), and Set (pre, post). TDJs are measured by participants indicating a value on a diagram with 22 lines of different lengths $(0.5 \mathrm{~cm}$ to $11.5 \mathrm{~cm}$, with $0.5 \mathrm{~cm}$ increments). Individual participant's TDJs were taken as the mean indicated values for the three tested distances $(4 \mathrm{~cm}, 6$ $\mathrm{cm}, 8 \mathrm{~cm}$ ) in $\mathrm{cm}$. Group medians are depicted by the central lines, and box limits indicate the 
25th and 75th percentile. The whiskers extend 1.5 times the interquartile range from the box limits.

Individual data points are depicted by circles. ${ }^{* * *} p_{\text {adjusted }}<.001$.

Fig. 4

Crossmodal interference in ms on the Crossmodal Congruency Task (CCT) for people with upper limb CRPS $(n=18)$ and their matched controls $(n=18)$. Data are split by Tool Arrangement (uncrossed $[\mathrm{U}]$, crossed [C]) and Visual Field (same [S], opposite [O]). We calculated crossmodal interference by subtracting reaction times for congruent trials from those for incongruent trials. Medians are depicted by the central lines, and box limits indicate the 25 th and 75 th percentile. The whiskers extend 1.5 times the interquartile range from the box limits. Individual data points are depicted by circles. ${ }^{* *} p_{\text {adjusted }}<.01$

Fig. 5

Crossmodal interference in ms on the Crossmodal Congruency Task (CCT) for people with lower limb CRPS $(n=18)$ and their matched controls $(n=18)$. Data are split by Tool Arrangement (uncrossed [U], crossed [C]) and Visual Field (same [S], opposite [O]). We calculated crossmodal interference by subtracting reaction times for congruent trials from those for incongruent trials. Medians are depicted by the central lines, and box limits indicate the 25 th and 75 th percentile. The whiskers extend 1.5 times the interquartile range from the box limits. Individual data points are depicted by circles. ${ }^{*} p_{\text {adjusted }}<.05$

Fig. 6 
Hand temperature asymmetries (absolute difference in temperature between hand of the affected and unaffected side of the body, in $\left.{ }^{\circ} \mathrm{C}\right)$ for people with upper limb CRPS $(n=18)$, lower limb CRPS ( $n$ $=18)$, and controls $(n=34)$, split by hand Arrangement (uncrossed, crossed). Blue lines indicate individuals who showed a numerical decrease in absolute hand temperature asymmetry for crossed hands (i.e. the expected spatially defined reduction of CRPS symptoms for crossed hands [54,55], compared to uncrossed hands. Orange lines indicate individuals who showed a numerical increase in hand temperature asymmetry for crossed hands compared to uncrossed hands. The black lines show the median hand-temperature asymmetries. 


\begin{tabular}{|c|c|c|c|c|c|c|c|c|c|c|c|c|}
\hline ID & Age & Sex & $\begin{array}{l}\text { Self- } \\
\text { reported } \\
\text { hand- } \\
\text { edness }\end{array}$ & $\begin{array}{l}\text { Location } \\
\text { \& type }\end{array}$ & $\begin{array}{c}\text { CRPS } \\
\text { Severity } \\
\text { Score [2] } \\
(/ 16)\end{array}$ & $\begin{array}{l}\text { Duration } \\
\text { (months) }\end{array}$ & $\begin{array}{c}\text { Baseline } \\
\text { pain } \\
(/ 10)\end{array}$ & $\begin{array}{l}\text { CRPS } \\
\text { BPD } \\
(/ 57)\end{array}$ & $\begin{array}{c}\text { SF- } \\
\text { MPQ- } \\
2 \\
(/ 10)\end{array}$ & $\begin{array}{l}\text { Inciting } \\
\text { event }\end{array}$ & Medication & Comorbidities \\
\hline UL1 & 30 & $\mathrm{~F}$ & $\mathrm{R}$ & R-II & 13 & 12 & 4 & 28 & 3.05 & $\begin{array}{l}\text { Crushed } \\
\text { elbow }\end{array}$ & $\begin{array}{l}\text { Gabapentin, } \\
\text { oxycodone, } \\
\text { nortriptyline, } \\
\text { paracetamol, } \\
\text { ibuprofen }\end{array}$ & \\
\hline UL3 & 61 & $M$ & $R$ & L-I & 12 & 48 & 4 & 16 & 1.27 & $\begin{array}{l}\text { Hand } \\
\text { surgery }\end{array}$ & $\begin{array}{l}\text { Paracetamol, } \\
\text { aspirin, } \\
\text { simvastatin, } \\
\text { methotrexate, }\end{array}$ & Frozen joints \\
\hline
\end{tabular}




\begin{tabular}{|c|c|c|c|c|c|c|c|c|c|c|c|c|}
\hline & & & & & & & & & & & $\begin{array}{l}\text { ramipril, } \\
\text { bisoprolol } \\
\text { fumarate, } \\
\text { levothyroxine } \\
\text { sodium, folic } \\
\text { acid }\end{array}$ & \\
\hline UL4 & 38 & $\mathrm{~F}$ & $\mathrm{R}$ & R-I & 10 & 59 & 7 & 38 & 7.41 & $\begin{array}{l}\text { Minor soft } \\
\text { tissue } \\
\text { damage of } \\
\text { the thumb }\end{array}$ & $\begin{array}{l}\text { Amitriptyline, } \\
\text { tramadol, } \\
\text { naproxen, } \\
\text { lidocaine }\end{array}$ & Pain in $R$ foot ${ }^{U}$ \\
\hline UL5 & 31 & $\mathrm{~F}$ & $\mathrm{~L}$ & $\mathrm{~L}-\mathrm{I}$ & 12 & 19 & 8 & 42 & 7.81 & Unknown & $\begin{array}{l}\text { Gabapentin, } \\
\text { naproxen, } \\
\text { cannabidiol, } \\
\text { buprenorphine, } \\
\text { omeprazole }\end{array}$ & $\begin{array}{l}\text { Fibromyalgia, } \\
\text { migraines, } \\
\text { polycystic } \\
\text { ovaries, } \\
\text { asthma }\end{array}$ \\
\hline UL6 & 64 & $\mathrm{~F}$ & $\mathrm{~L}$ & $\mathrm{~L}-\mathrm{I}$ & 10 & 79 & 2 & 5 & 2.50 & Elbow & Paracetamol & Fibromyalgia \\
\hline
\end{tabular}




\begin{tabular}{|c|c|c|c|c|c|c|c|c|c|c|c|c|}
\hline & & & & & & & & & & $\begin{array}{l}\text { spiral } \\
\text { fracture }\end{array}$ & & \\
\hline UL9 & 71 & $\mathrm{~F}$ & $\mathrm{R}$ & R-I & 10 & 76 & 4 & & 0.77 & $\begin{array}{l}\text { Soft tissue } \\
\text { injury of } \\
\text { the hand }\end{array}$ & Paracetamol & \\
\hline UL10 & 51 & $\mathrm{~F}$ & $\mathrm{R}$ & L-I & 13 & 57 & 8 & 28 & 6.32 & Shoulder & Gabapentin, & \\
\hline
\end{tabular}




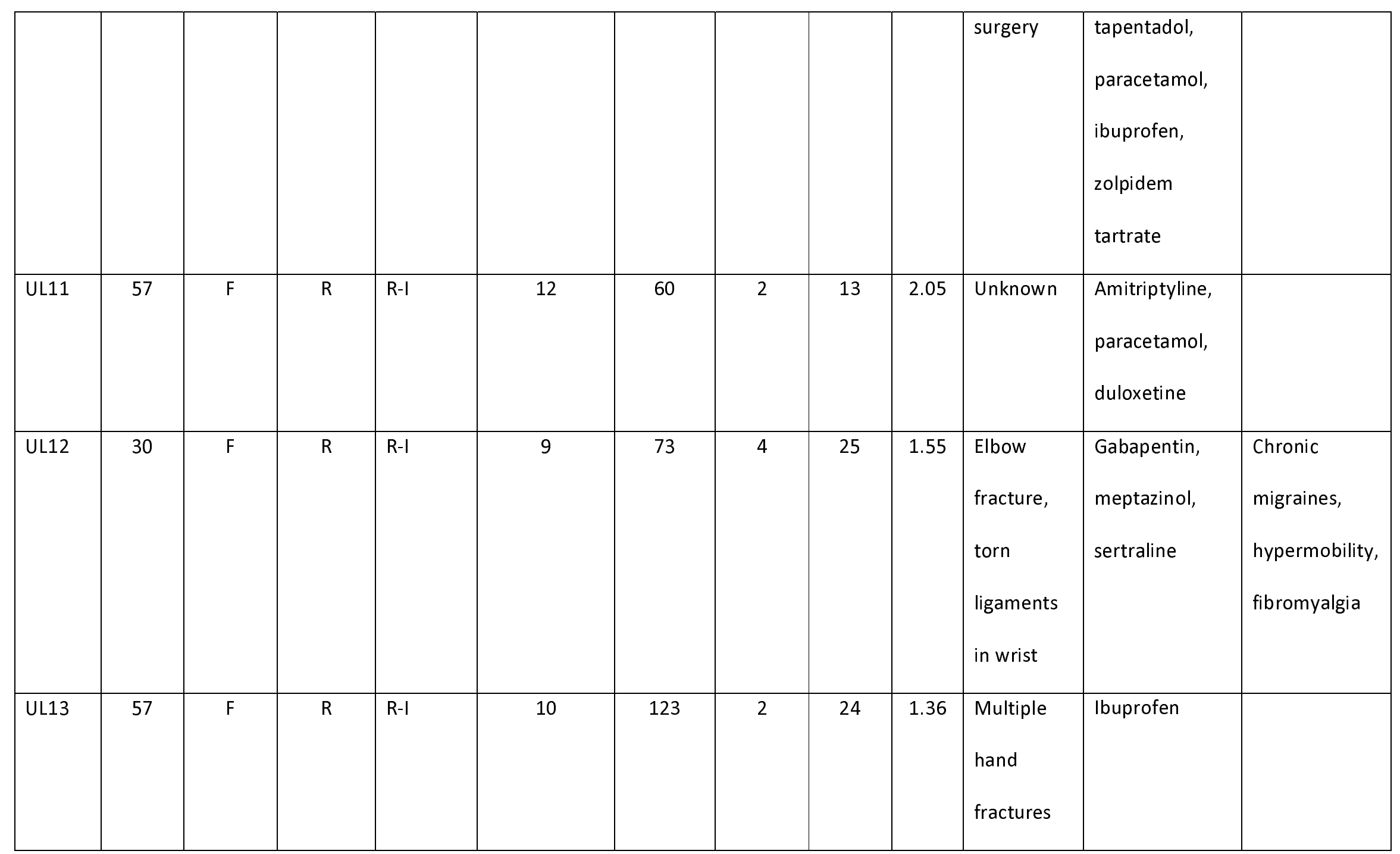




\begin{tabular}{|c|c|c|c|c|c|c|c|c|c|c|c|c|}
\hline $\mathrm{UL}^{\mathrm{T}} \mathrm{T}^{\top}$ & 53 & $F$ & $\mathrm{R}$ & L-I & 11 & 2 & 3 & 37 & 2.23 & $\begin{array}{l}\text { Elbow } \\
\text { fracture }\end{array}$ & $\begin{array}{l}\text { Amitriptyline, } \\
\text { co-codamol, } \\
\text { paracetamol, } \\
\text { lansoprazole }\end{array}$ & \\
\hline UL15 & 50 & $F$ & $R$ & L-I & 12 & 65 & 6 & 40 & 5.50 & $\begin{array}{l}\text { Breast cyst } \\
\text { drainage }\end{array}$ & $\begin{array}{l}\text { Gabapentin, } \\
\text { lidocaine, } \\
\text { baclofen, } \\
\text { rizatriptan, } \\
\text { citalopram } \\
\text { hydrobromide }\end{array}$ & \\
\hline UL17 & 49 & $F$ & $\mathrm{R}$ & L-I & 10 & 66 & 5 & 20 & 4.50 & $\begin{array}{l}\text { Wrist } \\
\text { surgery }\end{array}$ & $\begin{array}{l}\text { Tramadol, } \\
\text { tapentadol }\end{array}$ & $\begin{array}{l}\text { Arthritis, } \\
\text { migraines }\end{array}$ \\
\hline UL18 & 38 & $F$ & $\mathrm{R}$ & $L-I$ & 9 & 34 & 7 & 14 & 7.41 & Surgery for & Morphine, & Migraines \\
\hline
\end{tabular}




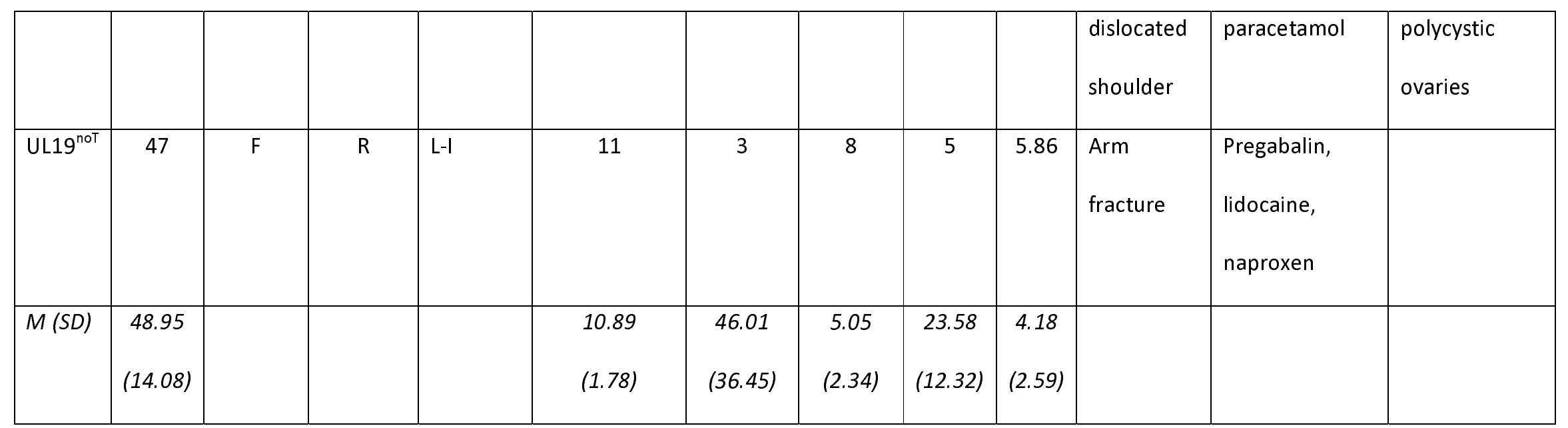

$\mathrm{T}=$ temperature recording only. noT $=$ no temperature recordings. $\mathrm{U}=$ undiagnosed. Duration $=$ months since CRPS diagnosis. SF-MPQ- $2=\mathrm{Short}-\mathrm{form}$ McGill Pain Questionnaire [1], total score. CRPS BPD = Bath CRPS Body Perception Distortion scale [3]. 
[1] Dworkin RH, Turk DC, Revicki DA, Harding G, Coyne KS, Peirce-Sandner S, Bhagwat D, Everton D, Burke LB, Cowan P. Development and initial validation of an expanded and revised version of the Short-form McGill Pain Questionnaire (SF-MPQ-2). PAIN ${ }^{\circledR}$ 2009;144(1-2):35-42.

[2] Harden RN, Maihofner C, Abousaad E, Vatine J-J, Kirsling A, Perez RS, Kuroda M, Brunner F, Stanton-Hicks M, Marinus J. A prospective, multisite, international validation of the Complex Regional Pain Syndrome Severity Score. Pain 2017;158(8):1430-1436.

[3] Lewis JS, McCabe CS. Body perception disturbance (BPD) in CRPS. Practical Pain Management 2010:60-66. 


\begin{tabular}{|c|c|c|c|c|c|c|c|c|c|c|c|c|}
\hline ID & Age & Sex & $\begin{array}{l}\text { Self- } \\
\text { reported } \\
\text { Hand- } \\
\text { edness }\end{array}$ & $\begin{array}{l}\text { Location } \\
\text { \& type }\end{array}$ & $\begin{array}{l}\text { CRPS } \\
\text { Severity } \\
\text { Score } \\
{[2]} \\
\text { (/16) }\end{array}$ & $\begin{array}{l}\text { Duration } \\
\text { (months) }\end{array}$ & $\begin{array}{l}\text { Baseline } \\
\text { pain } \\
(/ 10)\end{array}$ & $\begin{array}{c}\text { CRPS } \\
\text { BPD } \\
(/ 57)\end{array}$ & $\begin{array}{c}\text { SF- } \\
\text { MPQ- } \\
2 \\
(/ 10)\end{array}$ & Inciting event & Medication & Comorbidities \\
\hline LL1 & 48 & $F$ & $\mathrm{R}$ & L-I & 13 & 78 & 7 & 24 & 4.64 & Unknown & $\begin{array}{l}\text { Amitriptyline, } \\
\text { pregabalin, } \\
\text { morphine, } \\
\text { naproxen, } \\
\text { omeprazole, } \\
\text { simvastatin }\end{array}$ & $\begin{array}{l}\text { Tendonitis, } \\
\text { Raynaud } \\
\text { syndrome, } \\
\text { sleep apnoea }\end{array}$ \\
\hline LL2 & 42 & $M$ & $\mathrm{R}$ & R-I & 13 & 8 & 8 & 56 & 8.59 & Slipped disk & $\begin{array}{l}\text { Gabapentin, } \\
\text { epidural, } \\
\text { paracetamol, } \\
\text { ibuprofen }\end{array}$ & $\begin{array}{l}\text { Arthritis, } \\
\text { osteoporosis }\end{array}$ \\
\hline LL3 & 33 & $M$ & $\mathrm{R}$ & $\mathrm{L}-\mathrm{I}$ & 13 & 30 & 8 & 36 & 5.41 & Ankle & Gabapentin, & CRPS arm (L; \\
\hline
\end{tabular}




\begin{tabular}{|c|c|c|c|c|c|c|c|c|c|c|c|c|}
\hline & & & & & & & & & & fracture & $\begin{array}{l}\text { tramadol, } \\
\text { levocetirizine } \\
\text { dihydrochloride }\end{array}$ & $\begin{array}{l}\text { CRPS }^{\text {sev }}= \\
8 / 16), \text { IBS }\end{array}$ \\
\hline LL4 & 41 & $F$ & $\mathrm{R}$ & L-II & 14 & 56 & 8 & 17 & 4.32 & Spontaneous & None & $\begin{array}{l}\text { Arthritis, } \\
\text { lymphedema }\end{array}$ \\
\hline LL5 & 50 & $M$ & $\mathrm{R}$ & L-I & 13 & 43 & 8 & 21 & 5.64 & Shin fracture & Gabapentin & Arthritis \\
\hline LL6 & 32 & $F$ & $\mathrm{R}$ & $\mathrm{L}-\mathrm{I}$ & 11 & 48 & 7 & 38 & 4.45 & Knee surgery & $\begin{array}{l}\text { Paracetamol, } \\
\text { ibuprofen }\end{array}$ & Hypermobility \\
\hline LL7 & 56 & $F$ & $\mathrm{~L}$ & L-I & 9 & 13 & 5 & 30 & 2.05 & $\begin{array}{l}\text { Abdominal } \\
\text { surgery }\end{array}$ & $\begin{array}{l}\text { Codeine, } \\
\text { naproxen, } \\
\text { zopiclone }\end{array}$ & CRPS torso (L) \\
\hline LL8 & 46 & $F$ & $\mathrm{R}$ & L-I & 11 & 170 & 6 & 35 & 7.45 & $\begin{array}{l}\text { Abdominal } \\
\text { surgery }\end{array}$ & $\begin{array}{l}\text { Naproxen, } \\
\text { citalopram } \\
\text { hydrobromide }\end{array}$ & \\
\hline LL9 & 52 & $\mathrm{~F}$ & $\mathrm{R}$ & L-I & 14 & 37 & 10 & 22 & 8.09 & Unknown $^{a}$ & None & Back pain \\
\hline
\end{tabular}




\begin{tabular}{|c|c|c|c|c|c|c|c|c|c|c|c|c|}
\hline LL10 & 57 & $F$ & $\mathrm{R}$ & R-II & 14 & 349 & 10 & 17 & 6.36 & $\begin{array}{l}\text { Foot, ankle, } \\
\text { and skull } \\
\text { fracture }\end{array}$ & $\begin{array}{l}\text { Pregabalin, } \\
\text { morphine } \\
\text { sulphate, } \\
\text { paracetamol }\end{array}$ & \\
\hline LL11 & 32 & $M$ & $R$ & L-II & 15 & 17 & 7 & 24 & 7.14 & Crushed foot & $\begin{array}{l}\text { Tramadol, } \\
\text { pregabalin, } \\
\text { lidocaine }\end{array}$ & \\
\hline LL12 & 28 & $F$ & $\mathrm{~L}$ & L-I & 14 & 21 & 9 & 21 & 7.55 & Foot surgery & $\begin{array}{l}\text { Pregabalin, } \\
\text { paracetamol }\end{array}$ & \\
\hline LL13 & 59 & $M$ & $R$ & L-II & 13 & 113 & 7 & 45 & 5.95 & $\begin{array}{l}\text { Ankle } \\
\text { compound } \\
\text { fracture }\end{array}$ & $\begin{array}{l}\text { Amitriptyline, } \\
\text { gabapentin, } \\
\text { paracetamol, } \\
\text { duloxetine, } \\
\text { atorvastatin, } \\
\text { colecalciferol, } \\
\text { felodipine }\end{array}$ & $\begin{array}{l}\text { Knee pain (L), } \\
\text { shoulder pain } \\
\text { (L), type } 2 \\
\text { diabetes }\end{array}$ \\
\hline
\end{tabular}




\begin{tabular}{|c|c|c|c|c|c|c|c|c|c|c|c|c|}
\hline LL14 & 43 & $F$ & $\mathrm{R}$ & R-II & 14 & 18 & 8 & 45 & 8.36 & Foot fracture & $\begin{array}{l}\text { Gabapentin, } \\
\text { levocetirizine } \\
\text { dihydrochloride, } \\
\text { prednisolone, } \\
\text { adrenaline (for } \\
\text { allergy to nuts, } \\
\text { latex, penicillin) }\end{array}$ & \\
\hline LL15 & 59 & $\mathrm{~F}$ & $\mathrm{R}$ & L-I & 12 & 21 & 7 & 25 & 7.68 & $\begin{array}{l}\text { Crushed } \\
\text { ankle }\end{array}$ & $\begin{array}{l}\text { Amitriptyline, } \\
\text { lidocaine, } \\
\text { atorvastatin, } \\
\text { amlodipine } \\
\text { besilate }\end{array}$ & \\
\hline LL16 & 49 & $M$ & $R$ & R-I & 9 & 16 & 9 & 50 & 8.14 & Crushed foot & $\begin{array}{l}\text { Pregabalin, } \\
\text { codeine, } \\
\text { nortriptyline, } \\
\text { paracetamol }\end{array}$ & $\begin{array}{l}\text { Phantom pain } \\
\text { from } \\
\text { amputated } \\
\text { toe (R), back }\end{array}$ \\
\hline
\end{tabular}




\begin{tabular}{|c|c|c|c|c|c|c|c|c|c|c|c|c|}
\hline & & & & & & & & & & & & $\begin{array}{l}\text { and bilateral } \\
\text { shoulder pain, } \\
\text { type } 2 \\
\text { diabetes, } \\
\text { hypertension }\end{array}$ \\
\hline LL17 & 33 & M & $\mathrm{R}$ & R-I & 14 & 28 & 5 & 42 & 8.05 & Crushed leg & $\begin{array}{l}\text { Pregabalin, } \\
\text { tramadol, } \\
\text { nortriptyline, } \\
\text { buprenorphine, } \\
\text { sertraline }\end{array}$ & \\
\hline LL18 & 41 & $\mathrm{~F}$ & $\mathrm{R}$ & L-I & 12 & 35 & 5 & 41 & 6.91 & Knee surgery & $\begin{array}{l}\text { Amitriptyline, } \\
\text { zomorph, } \\
\text { morphine } \\
\text { sulphate, } \\
\text { paracetamol, } \\
\text { citalopram }\end{array}$ & $\begin{array}{l}\text { Knee pain }(\mathrm{R}) \text {, } \\
\text { back pain }\end{array}$ \\
\hline
\end{tabular}




\begin{tabular}{|l|l|l|l|l|l|l|l|l|l|l|l|}
\hline & & & & & & & & & & & hydrobromide, \\
omeprazole & \\
\hline$M(S D)$ & 44.50 & & & & 12.67 & 61.06 & 7.59 & 32.72 & 6.39 & & \\
& $(10.04)$ & & & & $(1.71)$ & $(82.58)$ & $(1.46)$ & $(11.99)$ & (1.79) & & \\
\hline
\end{tabular}

Duration $=$ months since CRPS diagnosis. SF-MPQ-2 = Short-form McGill Pain Questionnaire [1], total score. CRPS BPD = Bath CRPS Body Perception

Distortion scale [3]. CRPS ${ }^{\text {sev }}=$ CRPS Severity Score [2] (/16). a = symptoms may have been present since she had polio as a child. noS = no other symptoms.

Duration = Months since CRPS diagnosis was received. IBS = irritable bowel syndrome. 
[1] Dworkin RH, Turk DC, Revicki DA, Harding G, Coyne KS, Peirce-Sandner S, Bhagwat D, Everton D, Burke LB, Cowan P. Development and initial validation of an expanded and revised version of the Short-form McGill Pain Questionnaire (SF-MPQ-2). PAIN ${ }^{\circledR}$ 2009;144(1-2):35-42.

[2] Harden RN, Maihofner C, Abousaad E, Vatine J-J, Kirsling A, Perez RS, Kuroda M, Brunner F, Stanton-Hicks M, Marinus J. A prospective, multisite, international validation of the Complex Regional Pain Syndrome Severity Score. Pain 2017;158(8):1430-1436.

[3] Lewis JS, McCabe CS. Body perception disturbance (BPD) in CRPS. Practical Pain Management 2010:60-66. 


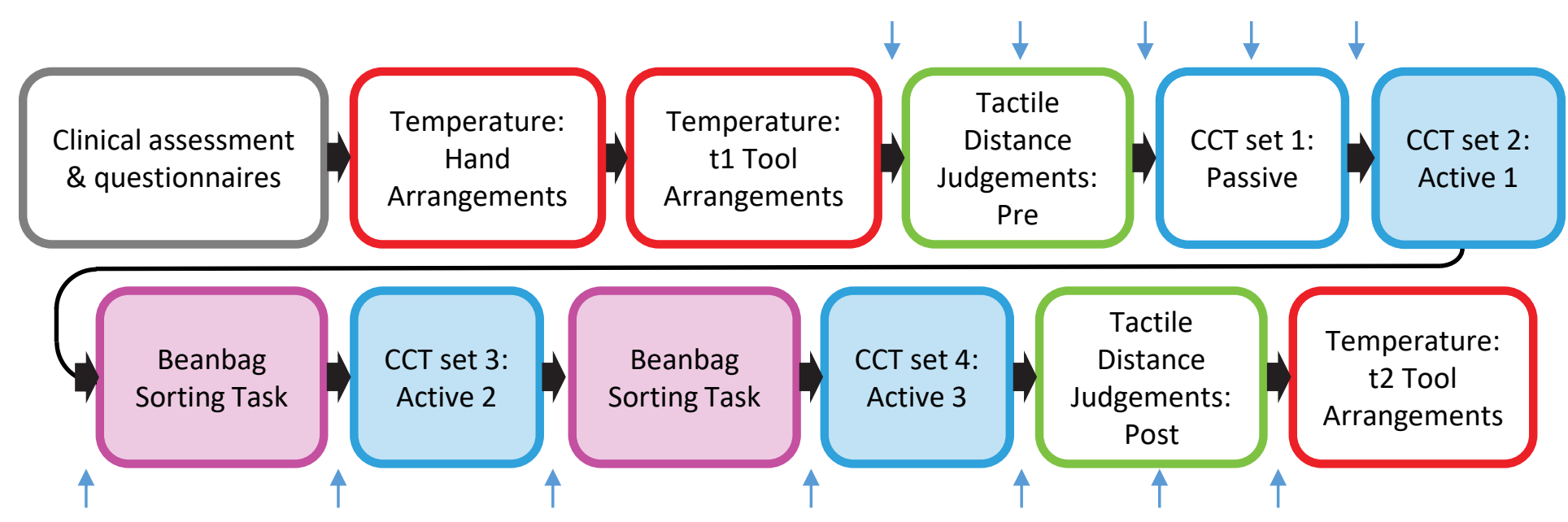




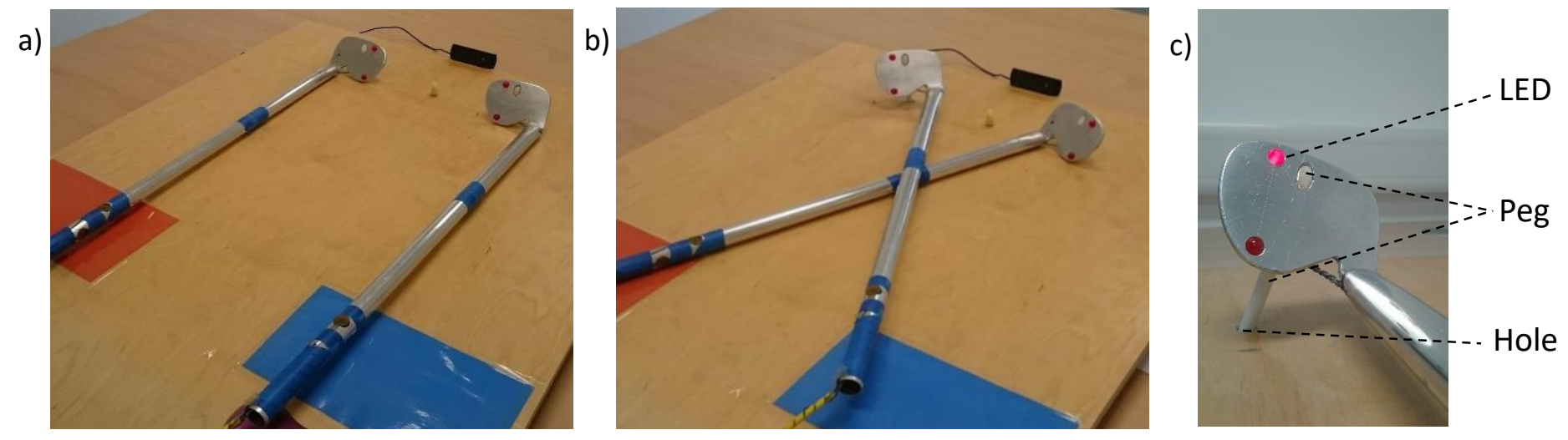



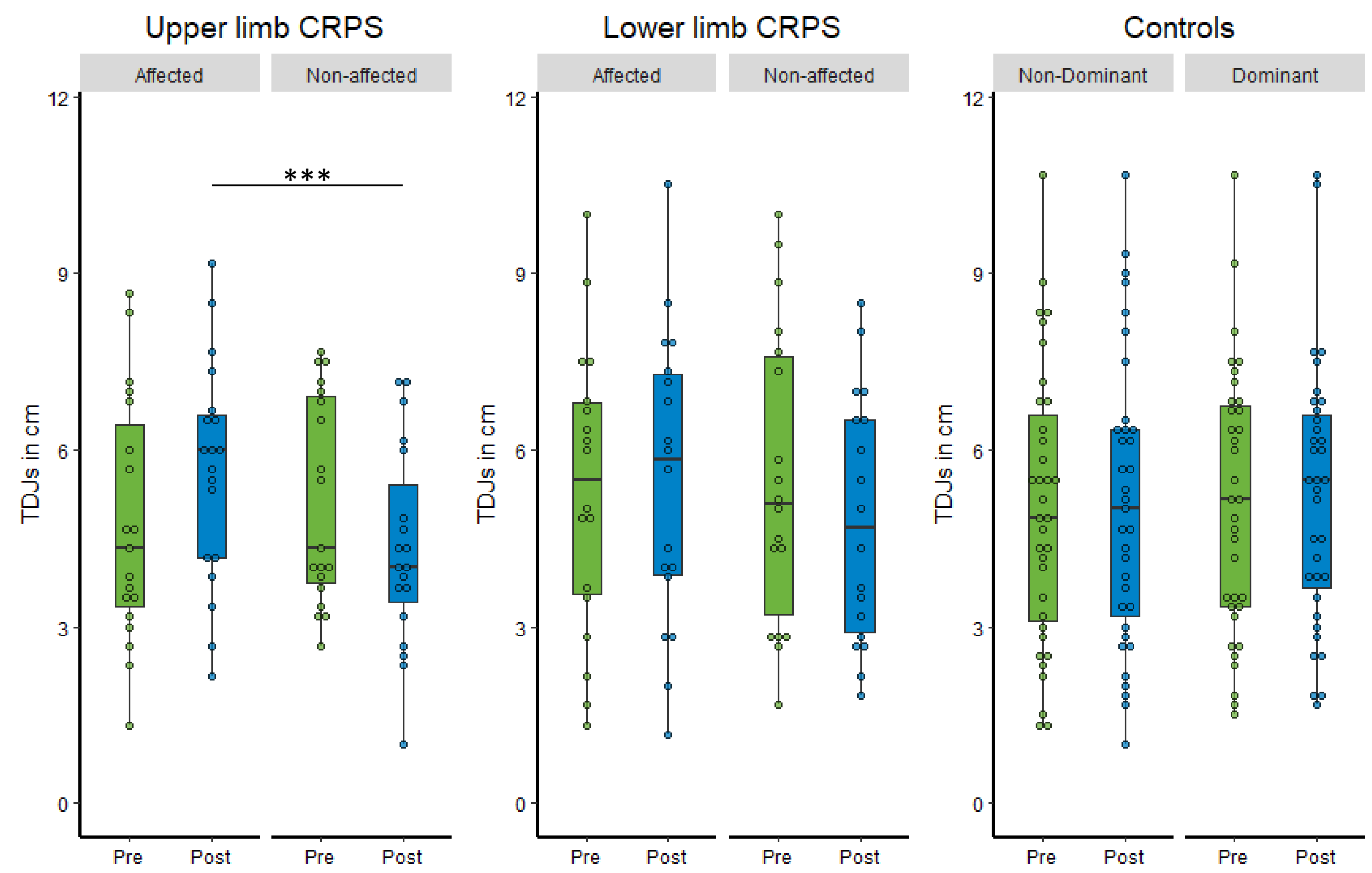


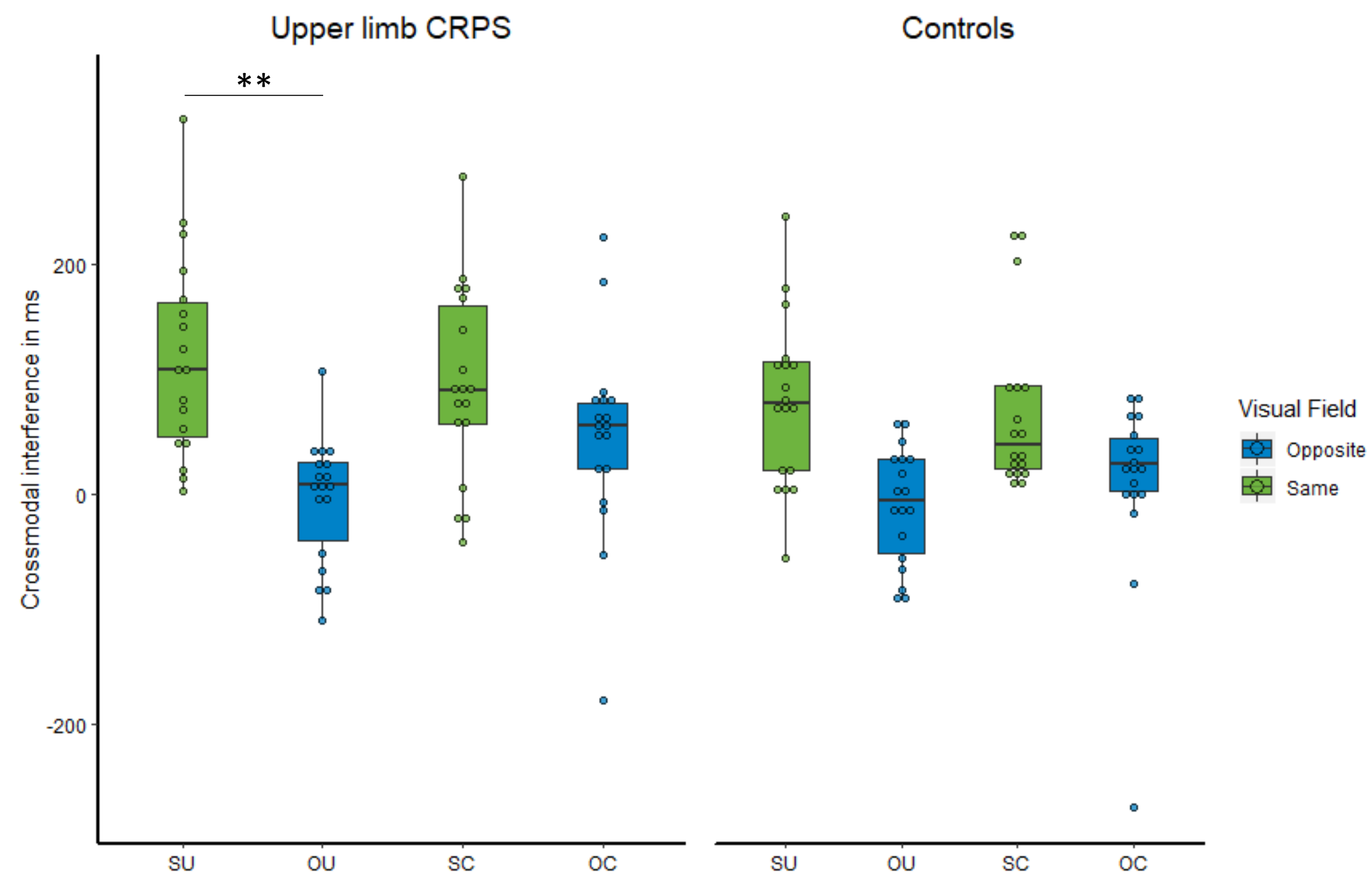




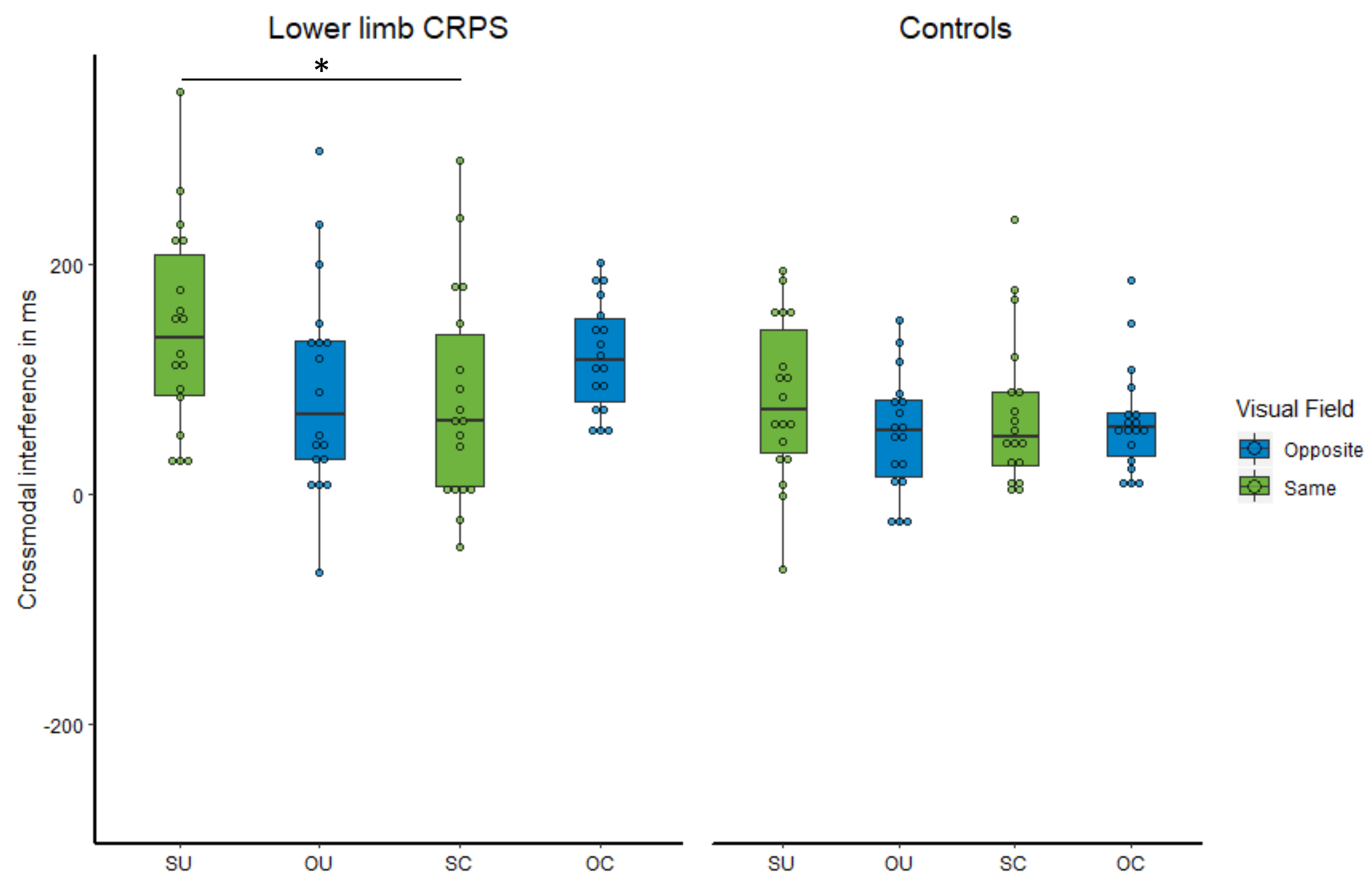



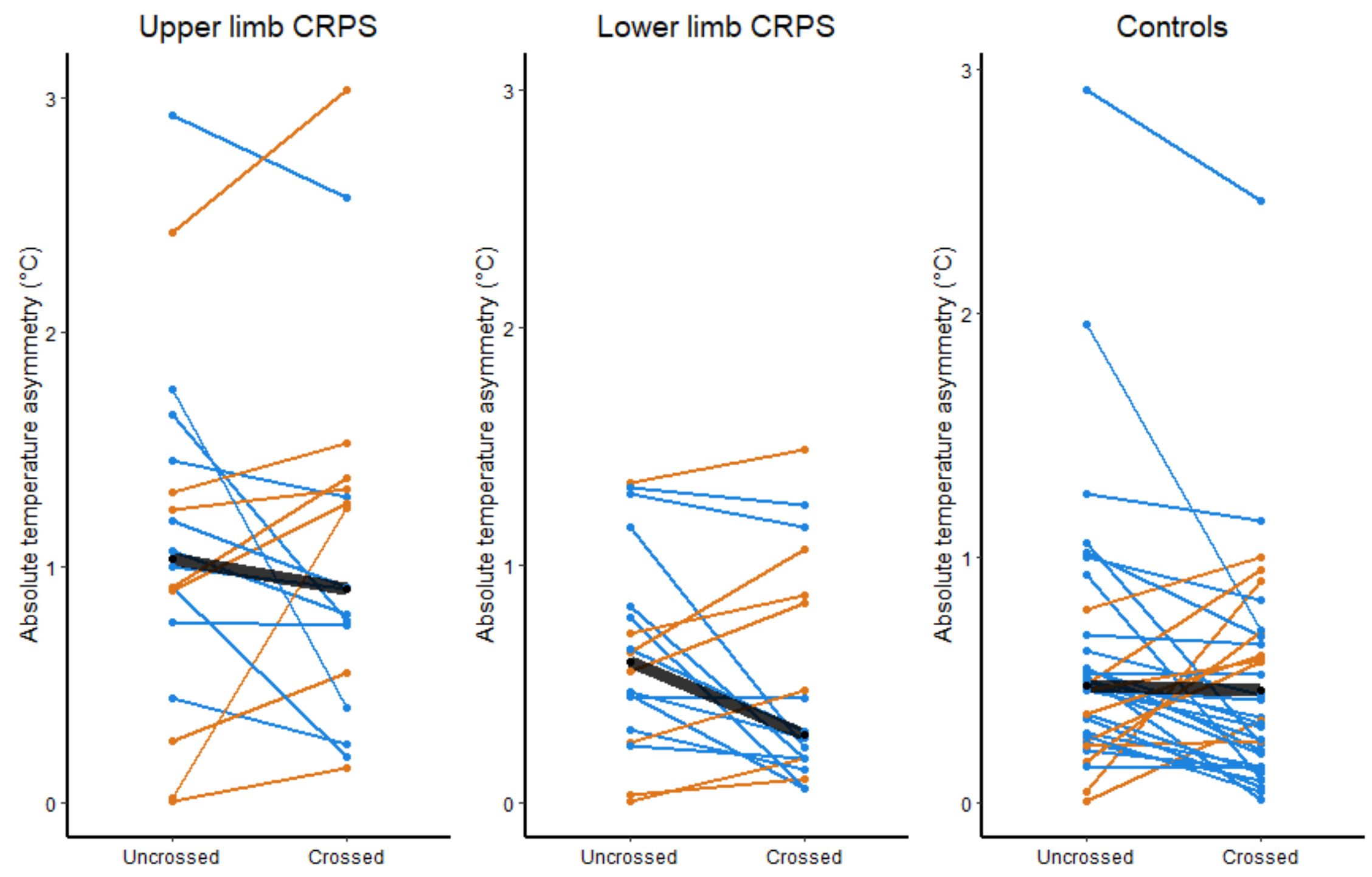